\title{
A review of new developments in the Friedel-Crafts alkylation - From green chemistry to asymmetric catalysis
}

Magnus Rueping ${ }^{* 1}$ and Boris J. Nachtsheim ${ }^{* 2}$

\section{Review}

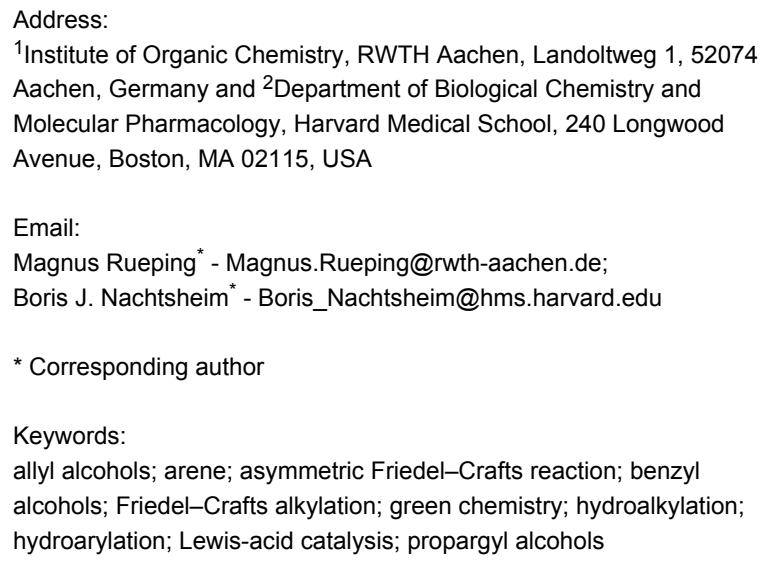

${ }^{1}$ Institute of Organic Chemistry, RWTH Aachen, Landoltweg 1, 52074 Aachen, Germany and ${ }^{2}$ Department of Biological Chemistry and Molecular Pharmacology, Harvard Medical School, 240 Longwood Avenue, Boston, MA 02115, USA

Email:

Magnus Rueping * Magnus.Rueping@rwth-aachen.de;

Boris J. Nachtsheim* - Boris_Nachtsheim@hms.harvard.edu

* Corresponding author

Keywords:

allyl alcohols; arene; asymmetric Friedel-Crafts reaction; benzyl alcohols; Friedel-Crafts alkylation; green chemistry; hydroalkylation; hydroarylation; Lewis-acid catalysis; propargyl alcohols

Beilstein Journal of Organic Chemistry 2010, 6, No. 6. doi:10.3762/bjoc.6.6

Received: 10 September 2009

Accepted: 17 November 2009

Published: 20 January 2010

Editor-in-Chief: J. Clayden

(c) 2010 Rueping and Nachtsheim; licensee Beilstein-Institut. License and terms: see end of document.

\begin{abstract} lective Friedel-Crafts-type alkylations will be highlighted.

\section{Introduction}

In 1887 Charles Friedel and James Mason Crafts isolated amylbenzene after the treatment of amyl chloride with $\mathrm{AlCl}_{3}$ in benzene (Scheme 1) [1]. This was not only one of the first descriptions of a Lewis acid used in organic synthesis but also the first example of what was later to be called Friedel-Crafts alkylation (FC alkylation) after its inventors. Today Friedel-Crafts alkylations remain the method of choice for the alkylation of arenes and heteroarenes.
\end{abstract}

The development of efficient Friedel-Crafts alkylations of arenes and heteroarenes using only catalytic amounts of a Lewis acid has gained much attention over the last decade. The new catalytic approaches described in this review are favoured over classical Friedel-Crafts conditions as benzyl-, propargyl- and allyl alcohols, or styrenes, can be used instead of toxic benzyl halides. Additionally, only low catalyst loadings are needed to provide a wide range of products. Following a short introduction about the origin and classical definition of the Friedel-Crafts reaction, the review will describe the different environmentally benign substrates which can be applied today as an approach towards greener processes. Additionally, the first diastereoselective and enantiose- 
Over the intervening years many other Lewis acids including $\mathrm{BF}_{3}, \mathrm{BeCl}_{2}, \mathrm{TiCl}_{4}, \mathrm{SbCl}_{5}$ or $\mathrm{SnCl}_{4}$ have been described as catalysts for the FC alkylation. Furthermore, strong Brønsted-acids including sulfuric acid, hydrofluoric acid or super acids such as $\mathrm{HF} \cdot \mathrm{SbF}_{5}$ and $\mathrm{HSO}_{3} \mathrm{~F} \cdot \mathrm{SbF}_{5}$ have also been shown to accelerate this transformation. Despite the great importance of the Friedel-Crafts alkylation for organic synthesis it has major drawbacks since stoichiometric or super stoichiometric amounts of a Lewis acid or Brønsted acid and toxic alkyl halides have to be utilized leading to vast amounts of salt side products. With the need for more environmentally and economically benign processes, the development of FC reactions using only catalytic amounts of a metal or acid catalyst would be highly desirable. In addition, the substitution of the alkyl chlorides by other, less toxic, alkylating reagents such as alcohols would be a major improvement as water would be the only side product. Beyond this, the use of activated double bonds and styrenes would be even more efficient as no side products are to be expected. However, good ideas always need time to develop and grow and thus it is not surprising that it took more than 100 years from the initial invention of Friedel and Crafts in 1887 until the first catalytic FC alkylations with alcohols and styrenes as alkylating reagents were developed. Initial attempts in 1996 using $\mathrm{Sc}(\mathrm{OTf})_{3}$ and soon after with $\mathrm{Mo}(\mathrm{CO})_{6}$ as Lewis acid catalysts were consequently followed by a multitude of new methods employing a variety of Lewis- and Brønsted acids with decreasing catalyst loadings and in consequence increasing efficiencies (Figure 1).

With regard to the electrophiles employed in the FC alkylation protected or activated alcohols and styrenes have been found to be suitable alkylating reagents giving access to many functionalized arenes including 1,1-diarylalkanes, allyl- and prop-2ynylbenzenes. More recently diastereoselective and enantioselective Friedel-Crafts alkylations have been developed. In this review we intend to give an overview of the important developments that have primarily emerged over the last decade.

\section{Review}

\section{The FC alkylation with benzyl alcohols -} An efficient approach to 1,1-diarylalkanes

1,1-Diarylalkanes are important building blocks for the synthesis of many pharmaceuticals, agro- and fine chemicals (Figure 2).

Traditionally, 1,1-diarylalkanes have been prepared from benzyl halides under Friedel-Crafts conditions using stoichiometric amounts of a Lewis acid, such as $\mathrm{AlCl}_{3}$. With the need for more environmentally and economically benign processes, the Friedel-Crafts-type synthesis of 1,1-diarylalkanes using catalytic amounts of a metal or acid catalyst and more environmental friendly benzylation reagents are highly desirable. To

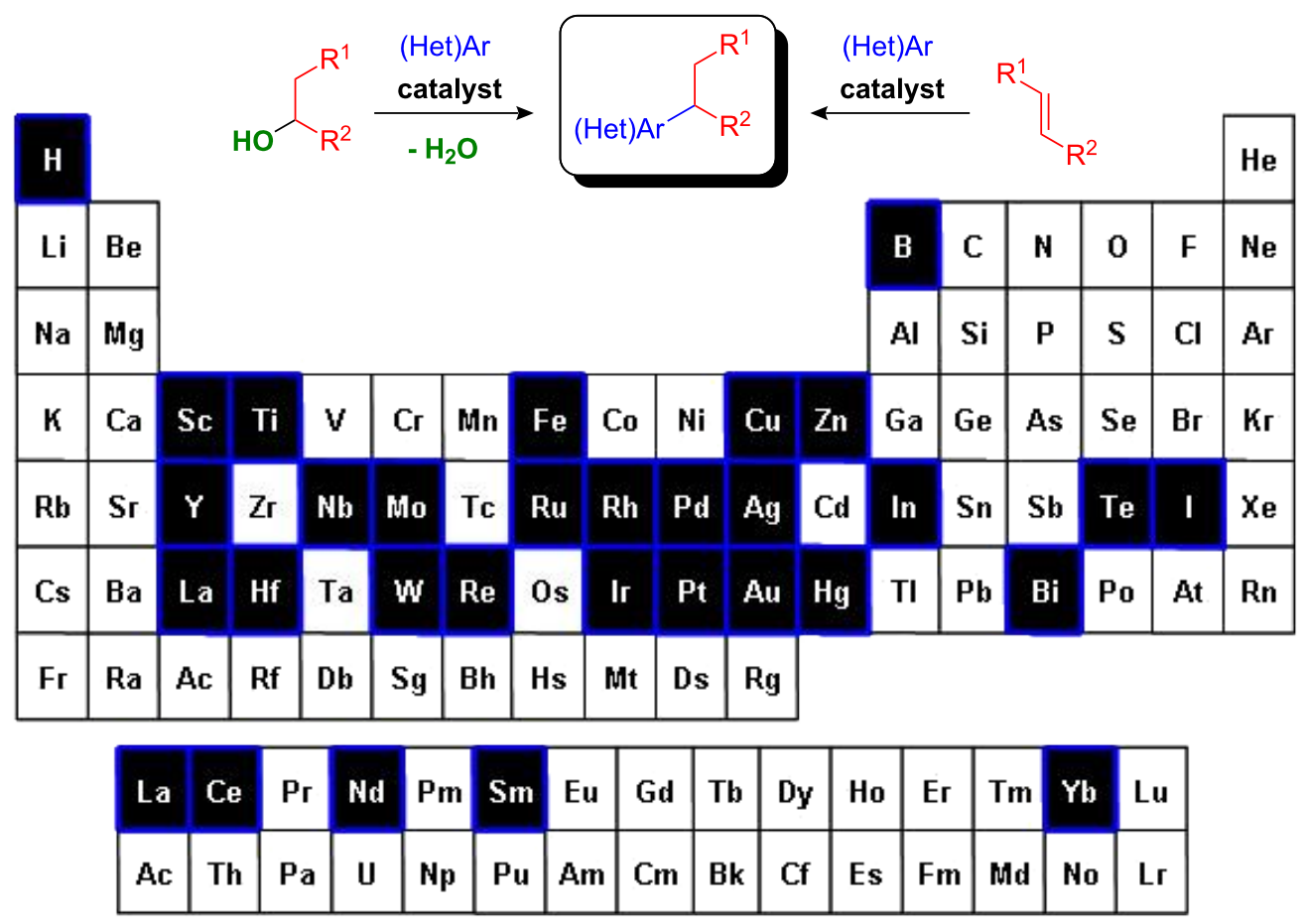

Figure 1: Most often used metal salts for catalytic FC alkylations and hydroarylations of arenes. 
<smiles>N#Cc1ccc(C(c2ccc(C#N)cc2)n2cncn2)cc1</smiles>

letrozole aromatase inhibitor<smiles>CC(C)(Oc1ccc(C2CCCc3ccccc32)cc1)C(=O)O</smiles>

nafenopin peroxisome proliferator<smiles>COc1ccc(Cc2nccc3cc(OC)c(OC)cc23)cc1OC</smiles>

papaverin against erectile dysfunctions<smiles>CCC(c1ccccc1)c1c(O)c2ccccc2oc1=O</smiles>

phenprocoumone thrombosis prophylaxis<smiles>COc1ccc(-c2oc3c(C(C)c4ccc(O)cc4)c(O)cc(O)c3c(=O)c2OC)cc1</smiles>

haplopappin plant Haplopappus foliosus<smiles>CC(C1=C(CCN(C)C)Cc2ccccc21)c1ccccn1</smiles>

dimetindene histamine $\mathrm{H}_{1}$ agonist<smiles>CCOC(C)(CC)Oc1ccc(Cc2ccc(Cl)cc2)cc1</smiles>

beclobrate lipoprotein regulator<smiles>COc1ccc(OC)c(Cc2cnc3nc(N)nc(N)c3c2C)c1</smiles>

piritrexim dihydrofolate reductase inhibitor

Figure 2: 1,1-diarylalkanes with biological activity.

this end substantial progress has been made and different benzyl halide substitutes, including free and protected alcohols as well as tosylamides have been introduced (Scheme 2).

$$
\begin{aligned}
& \text { 1,1-diarylalkane } \\
& \text { side product }=\mathrm{H}-\mathrm{X} \quad \mathrm{H}_{2} \mathrm{O} \\
& \mathrm{HO}-\mathrm{R}^{\prime \prime}
\end{aligned}
$$

Scheme 2: Alkylating reagents and side products produced.

In particular benzyl alcohols have become a valuable alternative. Due to their availability, lower toxicity, and the fact that only stoichiometric amounts of water are generated as the side product the FC alkylation with benzyl-, allyl- and propargyl alcohols presented a first and important step toward an environmental friendly process.

In 1986, Uemura et al. investigated the chlorination of benzyland alkyl alcohols mediated by $\mathrm{SeCl}_{4}$ and $\mathrm{TeCl}_{4}$. While the reaction performed in non-aromatic solvents yielded the desired benzyl chlorides in good yields, an unexpected side reaction was observed in aromatic solvents such as toluene resulting in the 1,1-diarylalkane 3 in $83 \%$ yield (Scheme 2). The authors explained this observation with a chlorination of 1-phenylethanol 1 and subsequent FC alkylation of the formed benzyl chloride and toluene. However, more surprisingly the reaction yield could be improved to $93 \%$ if only catalytic amounts (10 mol\%) of $\mathrm{TeCl}_{4}$ were present (Scheme 3) [2].

Although the reaction was found by accident, this was probably the first description of a catalytic FC alkylation utilizing a benzyl alcohol.<smiles>CC(O)c1ccccc1</smiles>

1<smiles>CC(c1ccccc1)c1ccccc1</smiles>

3

1.2 equiv $\mathrm{TeCl}_{4}: 83 \%$

0.1 equiv $\mathrm{TeCl}_{4}: 93 \%$

(ortho/para: $11: 89$ )

Scheme 3: Initially reported $\mathrm{TeCl}_{4}$-mediated $\mathrm{FC}$ alkylation of 1-penylethanol with toluene. 


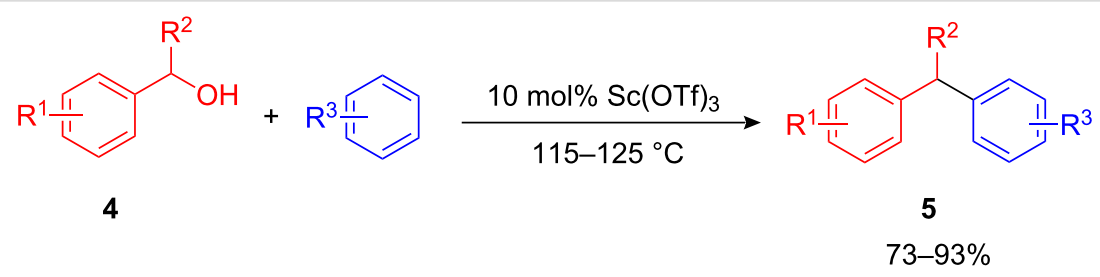

Scheme 4: Sc(OTf) 3 -catalyzed FC benzylation of arenes.

The first systematic investigations of catalytic FC benzylations were performed independently in 1996 and 1997 by Fukuzawa $[3,4]$ and Shimizu et al. [5]. While the latter used $10 \mathrm{~mol} \%$ $\mathrm{Mo}(\mathrm{CO})_{6}$ as the Lewis acid catalyst under the strict exclusion of air and moisture, the Fukuzawa group utilized $\mathrm{Sc}(\mathrm{OTf})_{3}$ as a water and air tolerant catalyst. Various arenes, including benzene, $p$-xylene, or mesitylenes were alkylated with benzyl alcohols $\mathbf{4}$ to afford the desired 1,1-diarylalkanes 5 in high yields (Scheme 4).

Other rare-earth trifluormethanesulfonates such as $\mathrm{Nd}(\mathrm{OTf})_{3}$ $\mathrm{Yb}(\mathrm{OTf})_{3}$ and $\mathrm{Sm}(\mathrm{OTf})_{3}$ showed similar reactivities and the reaction was later also performed in the ionic liquids [BMIM][OTf] and [BMIM][PF 6 [6]. Next to benzyl alcohol, allyl alcohols, dibenzylethers as well as arenecarbaldehydes and their corresponding acetals have been used as electrophilic component [7].

While FC alkylations with allyl alcohols and benzyl ethers are likely to have the same carbocationic reaction intermediate, the FC alkylation with arenecarbaldehydes 6 has to be different (Scheme 5). Mechanistic investigations revealed that propanediol is necessary for this reaction to proceed. In the first step of the reaction sequence a Lewis acid catalyzed acetalization of the aldehyde occurs and the acetal 7 is formed. The following nucleophilic attack of the arene yields diphenyl-substituted ether $\mathbf{8}$ as an intermediate which subsequently undergoes an intramolecular $[1,3]$ - or [1,5]-hydride shift resulting in the desired diarylmethanes $\mathbf{9}$ in good yields. Electron donating and electron withdrawing functional groups of aldehyde moiety are tolerated in this reductive Friedel-Crafts alkylation procedure. However, there is no clear correlation between the electron deficiency of the arenecarbaldehyde and the reaction yield [4].

Further mechanistic investigations were performed with 1,3propanediol-1,1,3,3- $d_{4}$ in order to provide more information about the observed hydride shift. Indeed deuterium was incorporated into the benzylic position and monodeuterated diphenylmethane was obtained in over $95 \%$ yield. This result and the fact that 3-hydroxypropanal $\mathbf{1 0}$ is a major side product strongly supports the mechanism of this reductive FC alkylation reaction.

Soon after the fundamental work by Fukuzawa and Shimizu, many catalytic FC benzylations using benzyl alcohols have been developed. These utilize for instance $\mathrm{Cl}_{2} \mathrm{Si}(\mathrm{OTf})_{2}$, $\mathrm{Hf}(\mathrm{OTf})_{4}$ [8], $\mathrm{Yb}(\mathrm{OTf})_{3}, \mathrm{La}(\mathrm{OTf})_{3}$ [9], $\mathrm{InCl}_{3}[10,11], \mathrm{NbCl}_{5}$ [12], heterobimetallic Ir-Sn-catalysts [13,14], H-mont [15], $\left[\mathrm{CpMoCl}(\mathrm{CO})_{3}\right] / o$-chloranil [16], strong Brønsted acids [17-19] calix[6]arene sulfonates [20] or molecular iodine [21,22] as catalysts.

In 2005 Beller et al. systematically tested the activity of various Lewis- and Brønsted acids in FC benzylations. They found that late transition metals such as $\mathrm{HAuCl}_{4}$ [23], $\mathrm{IrCl}_{3}$, [MesW(CO) $)_{3}$ ], $\mathrm{RhCl}_{3}, \mathrm{H}_{2} \mathrm{PdCl}_{4}, \mathrm{H}_{2} \mathrm{PtCl}_{6}$ [24] and $\mathrm{FeCl}_{3}$ [25]

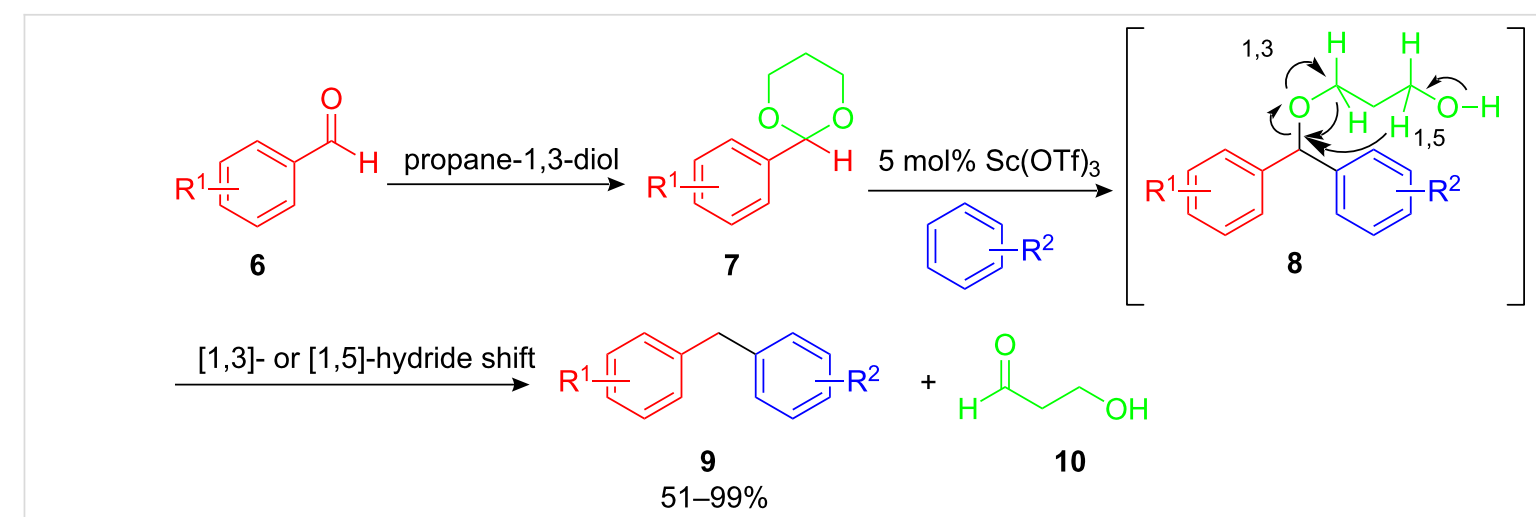

Scheme 5: Reductive FC alkylation of arenes with arenecarbaldehydes. 


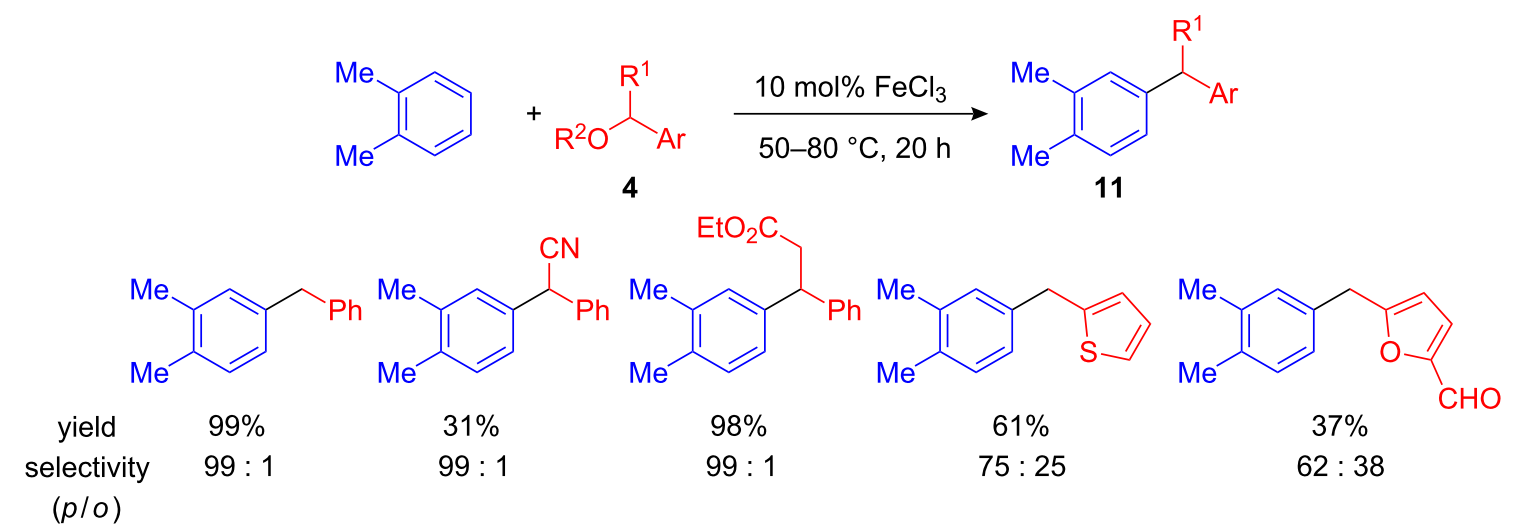

Scheme 6: Iron(III)-catalyzed FC benzylation of arenes and heteroarenes.

were the most effective. $\mathrm{FeCl}_{3}$, in particular, is an attractive alternative to rare-earth triflates since it is non-toxic, cheap and readily available. Different benzyl alcohols and acetates (Scheme 6, $\mathrm{R}^{1}=\mathrm{H}$ ) and 1-aryl alcohols $\left(\mathrm{R}^{1}=\mathrm{Me}\right.$ ) are tolerated in the reaction if $10 \mathrm{~mol}_{\%} \mathrm{FeCl}_{3}$ catalyst are applied. Even fairly unstable thiophene- and furan-2-carbaldehyde derived benzyl alcohols, cyano(phenyl)methyl acetate or 3-hydroxy-3phenylpropanoates and benzyl methyl ethers have been successfully applied as benzylation reagents [26].

Later, the same authors used gold(III) as a catalyst for an efficient one-pot synthesis of beclobrate, a well known fibric acid derivative with a potent hypolipidemic activity [23]. The straightforward synthesis was accomplished by reaction of readily available $p$-chlorobenzyl acetate (12) with 2-methyl-2- phenoxybutyrate 13 to give beclobrate (14) in 90\% yield. However, $10 \mathrm{~mol} \%$ of $\mathrm{HAuCl}_{4}$ had to be used (Scheme 7).

The Lewis- and Brønsted acid catalyzed activation of benzyl alcohols and derivatives is not only restricted to the Friedel-Crafts alkylation and the application of arenes but can additionally be extended to other nucleophiles. In particular, mono-substituted 1,3-diketones $\mathbf{1 7}$ and their derivatives are of great interest. Given that the alkylation typically requires stoichiometric amounts of a base and a toxic alkyl halide the development of an efficient environmentally benign route to 2-alkylated pentanediones $\mathbf{1 7 a - c}$ employing simply benzyl-, allyl- or propargyl alcohols $\mathbf{1 6}$ as alkylating reagents represented a valuable advancement (Scheme 8) [27-45].

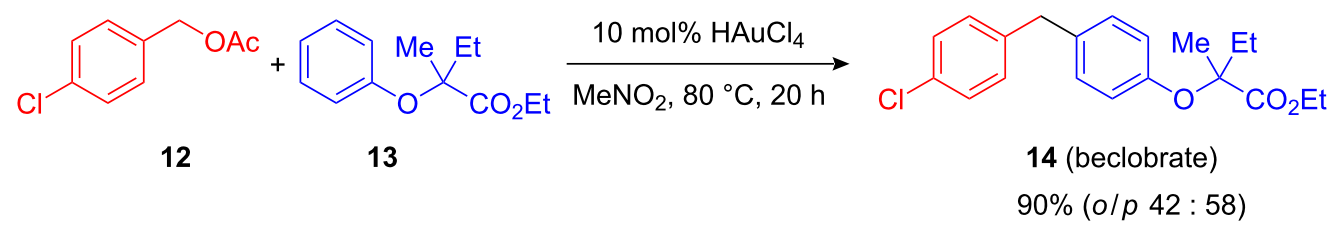

Scheme 7: A gold(III)-catalyzed route to beclobrate.

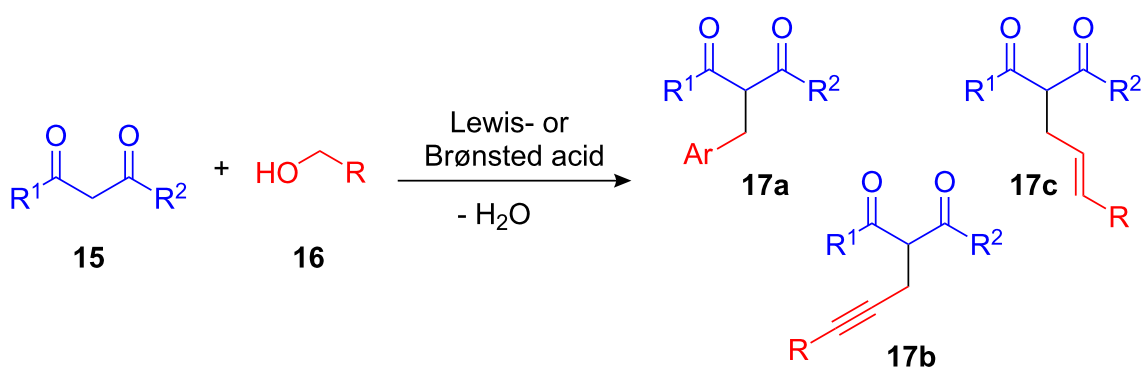


An example of this procedure represents the effective iron(III)catalyzed one-step synthesis of phenprocoumon (20), an anticoagulant of the warfarin-class that is widely used in thrombosis prophylaxis. Simply starting from 4-hydroxycoumarin (18) and 1-phenylpropan-1-ol (19), phenprocoumon (20) was obtained in $94 \%$ yield (Scheme 9) [27].<smiles>O=c1cc(O)c2ccccc2o1</smiles>

18

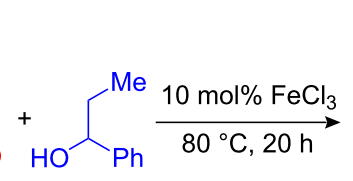

19<smiles>CCC(c1ccccc1)c1c(O)c2ccccc2oc1=O</smiles>

$2094 \%$ phenprocoumon

Scheme 9: Iron(III)-catalyzed synthesis of phenprocoumon.

As a suitable alternative to transition metals, bismuth salts have emerged as cheap, non-toxic, and readily available catalysts with Lewis acidic properties. Given that certain bismuth salts are compatible with air and moisture, the Rueping group decided to examine the bismuth-catalysed arylation and alkylation of benzyl alcohols. With small amounts of $\mathrm{Bi}(\mathrm{OTf})_{3}(0.5$ mol\%) they were able to benzylate arenes bearing methyl, methoxy or hydroxy functionalities as well as heteroarenes, including thiophenes or 3-methylindole with a good para/ortho/ meta regioselectivity (Scheme 10).

In addition, they successfully used benzyl acetates, 1-phenylethanol and $\beta$-hydroxy-substituted benzyl alcohols as alkylating reagents. Furthermore, an efficient intramolecular variant of this procedure starting from biaryl benzyl alcohol $\mathbf{2 3}$ led to substituted fluorenes $\mathbf{2 4}$ which have shown to be valuable scaffolds for blue light emitting polymers (Scheme 11A) [46]. A similar route to fluorenes and other annulated cycloalkanes $\mathbf{2 6}$ was subsequently developed utilizing nanostructured $\mathrm{MoO}_{3}$ (Scheme 11B) [47,48].

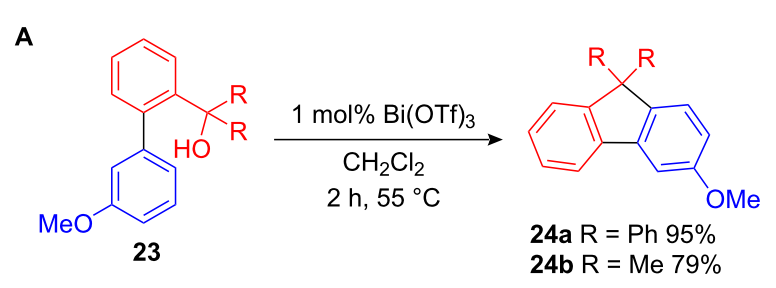

B

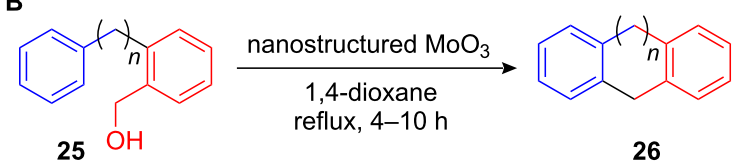

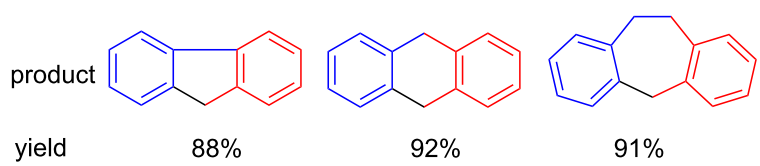

$\begin{array}{llll}\text { yield } & 88 \% & 92 \% & 91 \%\end{array}$

Scheme 11: (A) Bi(OTf) $)_{3}$-catalyzed intramolecular $\mathrm{FC}$ alkylation as an efficient route to substituted fulvenes. (B) Nanostructured $\mathrm{MoO}_{3}$ mediated intramolecular FC alkylation.

Recently, Kobayashi et al. reported a dehydrative nucleophilic substitution of benzyl alcohols in water employing a dodecylbenzenesulfonic acid (DBSA) as a surfactant-type Brønsted acid catalyst. With this green methodology a variety of carbonand heteroatom-centered nucleophiles were effectively applied resulting numerous diarylmethanes and 3 -substituted indoles. Moreover, this method could be extended to the C-glycosylation of 1-hydroxysugars and the products $\mathbf{2 8}$ were obtained in high yields and with remarkable anomeric ratios (Scheme 12) [49].

Recently, Cozzi et al. showed that FC benzylations can proceed even without adding a Lewis acid catalyst, just "on water" at 80 ${ }^{\circ} \mathrm{C}$. However, this method is restricted to reactive heteroarenes such as indole (30), pyrrole and nucleophiles including azides or acetylacetonates. Moreover, only highly reactive ferrocenyl

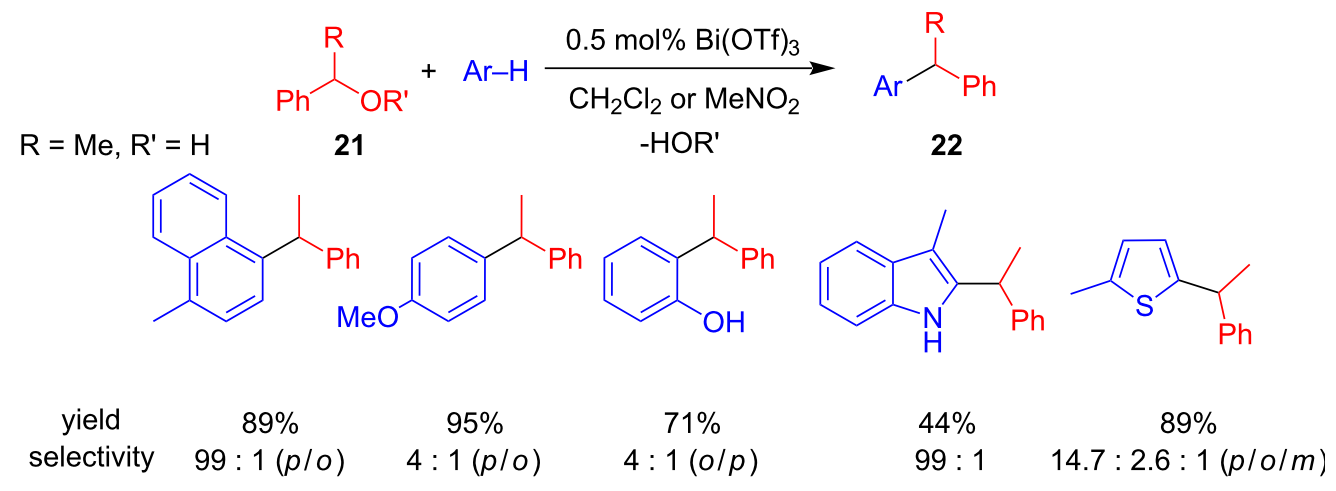




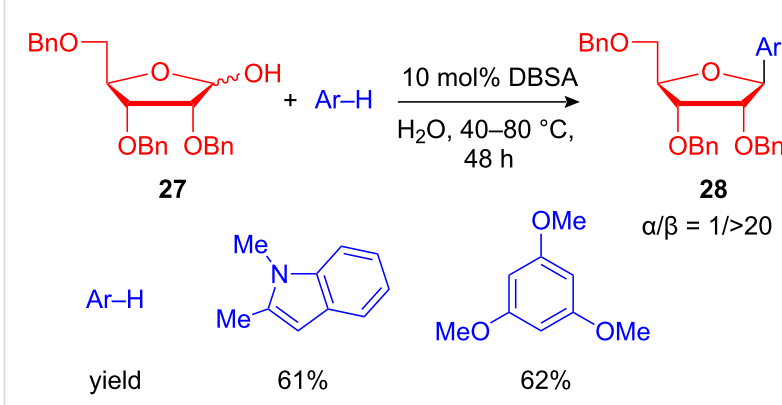

Scheme 12: FC-type glycosylation of 1,2-dimethylindole and trimethoxybenzene.

alcohols 29a or benzhydrols $\mathbf{2 9 b}-\mathbf{d}$, which result in highly stabilized carbocations upon elimination, can be used in this procedure (Scheme 13) [50].

An interesting domino reduction-alkylation procedure was recently developed by Peris et al. employing a versatile Ir-Cp*catalyst 33 (Scheme 14). This $N$-heterocyclic carbene Ir-complex is capable of catalyzing FC alkylations not only with benzyl alcohols and styrenes but also utilizing aldehydes and acetophenones 32, which are reduced prior to the FC-type alkylation in the same reaction vessel (Scheme 14). Here isop- ropanol can be used as a simple reducing reagent to afford the desired 1,1-diarylalkanes 34 in high yields after $12 \mathrm{~h}$ with just 1 mol\% of the Ir-complex 33. Thus this procedure widens the scope of electrophiles that can be used in environmental benign FC processes [51].

\section{Hydroarylations for the synthesis of 1,1- diarylalkanes}

The Friedel-Crafts benzylation of arenes using benzyl alcohols was discussed in the previous chapter. Even though it renders a convenient and environmental benign approach to 1,1diarylalkanes, there is still one stoichiometric side product formed during this transformation, namely water. Waste water treatment is an ongoing and expensive issue in large scale chemical processes; therefore, methodologies without the formation of water or other by-products would be even more desirable. As such, hydroarylations and hydroalkylations with a theoretical atom efficiency of $100 \%$ would solve these issues. The Friedel-Crafts-type 1,4-addition of arenes to unsaturated carbonyl compounds and their derivatives can be considered as Michael reactions. They have been extensively reviewed elsewhere and will be not discussed in this chapter [52-55]. For the synthesis of 1,1-diarylalkanes, efficient hydroarylation procedures employing styrenes and other activated double bonds are<smiles>[R]C(O)[C+]=Cc1ccc2[nH]cc(C([R])[R])c2c1</smiles>

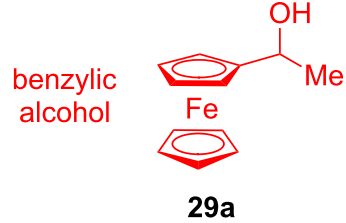

yield<smiles>OC1c2ccccc2Sc2ccccc21</smiles>

$29 b$

$82 \%$<smiles>OC1c2ccccc2Oc2ccccc21</smiles>

29c

$82 \%$<smiles>CN(C)c1ccc(C(O)c2ccc(N(C)C)cc2)cc1</smiles>

29d

$98 \%$

Scheme 13: FC alkylation with highly reactive ferrocenyl- and benzyl alcohols. The reaction proceeds even without Lewis acids just "on water".

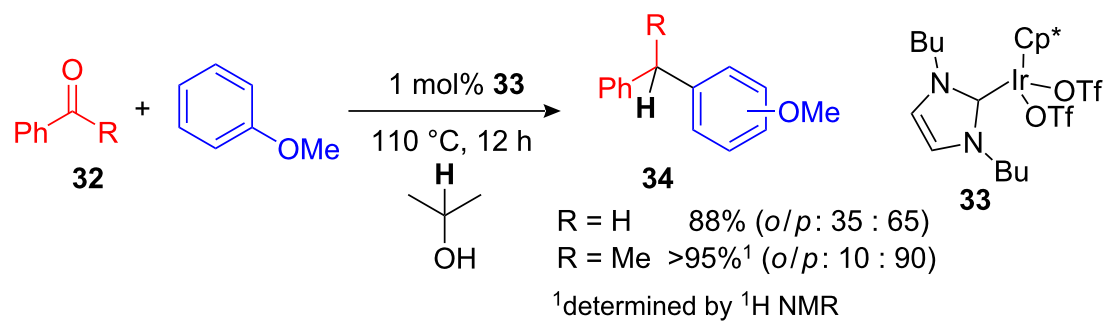

Scheme 14: Reductive FC alkylation of arenes with benzaldehyde and acetophenone catalyzed by the Ir-carbene complex 33 


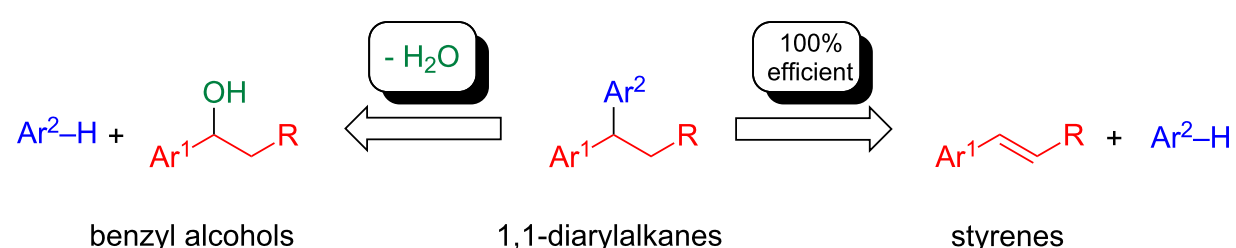

benzyl alcohols

1,1-diarylalkanes

styrenes

Scheme 15: Formal synthesis of 1,1-diarylalkanes from benzyl alcohols and styrenes.

needed (Scheme 15). Due to their availability, styrenes are most suitable substrates for potential hydroarylation methods and a fast synthesis of compound libraries should be feasible.

Although, the Murai reaction, the Ru-catalyzed ortho-alkylation of acetophenones with alkenes has been known since 1993 $[56,57]$, the direct substitution of arenes with styrenes is a development that has emerged in the last decade. Within this context, Shimizu and co-workers discovered a Lewis-acid-catalyzed substitution of arenes with olefins, such as styrene, $\alpha$ - and $\beta$-methylstyrene or cyclohexenes 35 (Scheme 16A) [5]. Various transition-metal compounds such as $\mathrm{Mo}(\mathrm{CO})_{6}, \mathrm{MoCl}_{5}$, $\mathrm{W}(\mathrm{CO})_{6}, \mathrm{H}_{2} \mathrm{IrCl}_{5}, \mathrm{Sc}(\mathrm{OTf})_{3}$ as well as several Brønsted acids were described, with $\mathrm{Mo}(\mathrm{CO})_{6}$ being the most efficient. Like other FC alkylations, the para-substituted product $\mathbf{3 6}$ was highly preferred. Interestingly, the hydroalkylation of anisole with citral (37) did not result in the expected alkyl-substituted anisole derivative. Instead, the diarylalkane $\mathbf{3 8}$ was obtained in $44 \%$ yield, most likely through a FC alkylation, cationic cyclization reaction cascade (Scheme 16B).

Unfortunately $10 \mathrm{~mol} \%$ of expensive, toxic and air- and moisture sensitive $\mathrm{Mo}(\mathrm{CO})_{6}$ was necessary for a successful transformation. It took almost nine years from this first discovery until Beller et al. and Rueping et al. developed Fe(III)- and
Bi(III)-catalyzed hydroarylations of arenes [58,59]. Although, $\mathrm{FeCl}_{3}$ is cheap, non-toxic and readily available, a high catalyst loading (10 mol\%) was necessary to obtain complete conversion. In comparison, $0.5 \mathrm{~mol} \%$ of $\mathrm{Bi}(\mathrm{OTf})_{3}$ were sufficient to give the desired 1,1-diarylalkanes after short reaction times in good to excellent yield and with good ortho/para selectivity. Although different arenes and heteroarenes, including thiophene can be efficiently alkylated, furans did not result in the desired products. In addition to styrene, dihydronaphthalene and $\alpha$-methylstyrene could be used as electrophiles. In the latter case, the formation of a quaternary carbon atom was possible. Although the product was isolated in lower yields (Scheme 17). Subsequently this method was expanded to other nucleophiles, such as 1,3-diketones [60].

Mirroring the $\mathrm{Bi}(\mathrm{OTf})_{3}$-catalyzed method, Hua et al. developed a $\mathrm{BiCl}_{3}$-catalyzed synthesis of 1,1-diarylalkanes starting from electron-rich arenes and styrenes. Additionally, they found that heating of styrene $\mathbf{4 1}$ in the presence of catalytic amounts of $\mathrm{BiCl}_{3}$ yielded substituted dihydroindenes $\mathbf{4 2}$ as a result of styrene dimerization. This reaction may proceed via an intermolecular ene reaction between styrene and the carbocationic intermediate $\mathbf{I}$ followed by an intramolecular FC alkylation of the resulting carbocationic 1,3-diarylpropane II (Scheme 18) [61].

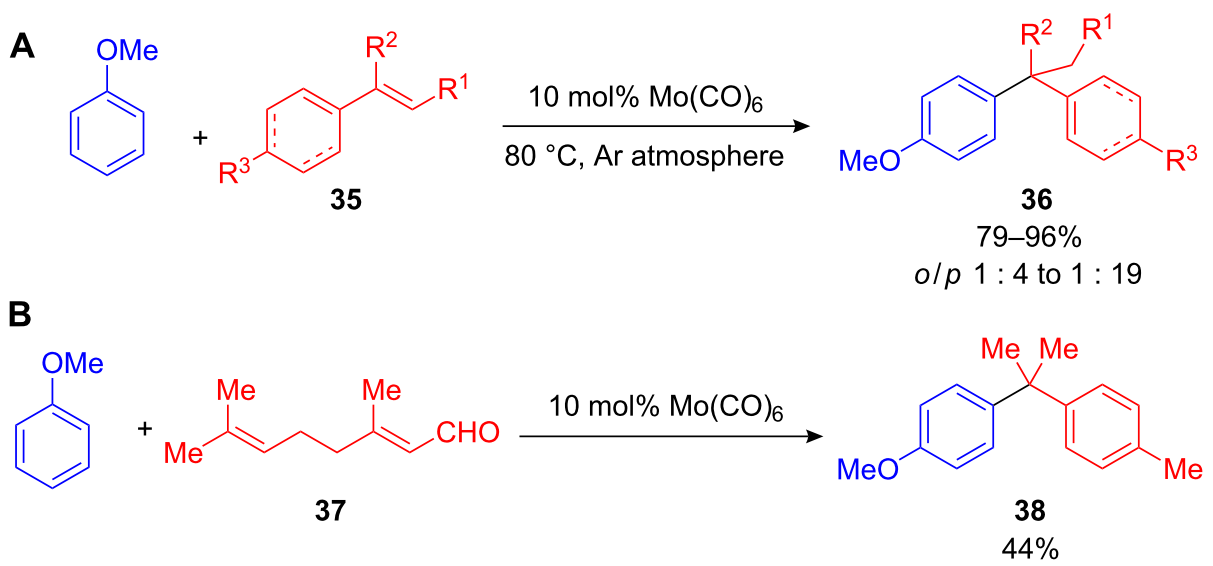

Scheme 16: (A) Mo-catalyzed hydroarylation of styrenes and cyclohexenes. (B) Hydroalkylation-cyclization cascade leading to 1,1-diarylalkane 38 from the linear precursor citral (37). 


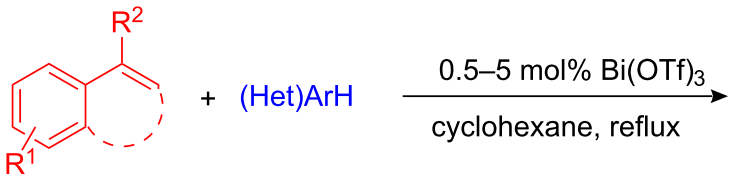

39<smiles>Cc1ccc(C(C)c2ccccc2)cc1C</smiles><smiles>CC(c1ccccc1)c1ccccc1O</smiles><smiles>CC(c1ccccc1)c1cccs1</smiles><smiles>COc1ccc(C(C)c2ccccc2F)cc1</smiles>

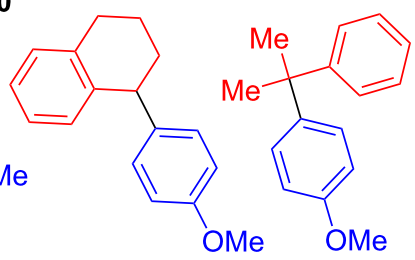

$65 \%$ $3.3: 1$<smiles></smiles>

$67 \%$

$10: 1$
$1: 3$

$6: 1$

$99: 1$ selectivity $(p / 0) \quad 10: 1$<smiles>[R][R]1ccc(C([R])=C)cc1</smiles>

41<smiles>CCC</smiles><smiles>[R]C(=CCC([R2])(C)c1cc#[R]cc1)c1ccccc1</smiles>

I

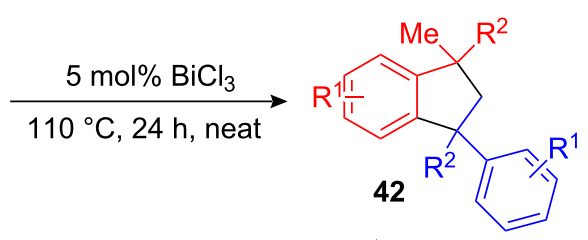

intramolecular FC alkylation<smiles>[R][R]C([R])(CC([R])(C)c1cc[R17]cc1)c1ccccc1</smiles>

II<smiles>Cc1ccc(C2(C)CC(C)(C)c3ccc(C)cc32)cc1</smiles>

yield $\quad 73 \%$

$56 \%$

$65 \%$

$92 \%$

Scheme 18: $\mathrm{BiCl}_{3}$-catalyzed ene/FC alkylation reaction cascade - $\mathrm{A}$ fast access to highly arylated dihydroindenes.

Next to the described procedures many related intermolecular FC-type alkylations with styrenes and activated double bonds have been developed using, for instance, $\mathrm{InCl}_{3} / \mathrm{SiO}_{2}[11]$, Iodine [62], $\mathrm{Ir}(\mathrm{III})$ [51], $\mathrm{AuCl}_{3} / \mathrm{AgSbF}_{6}$ [63], $\mathrm{AuCl}$ [64], and $\mathrm{PtCl}_{2}$ [65].

Within the row of heteroarenes, indole is one of the most important structural motifs due to its abundance in biologically active small molecules; thus their hydroarylations are particu- larly useful. A gold(I)-catalyzed hydroarylation of indoles with styrenes as well as with aliphatic and cyclic alkenes was developed by $\mathrm{Che}$ et al. [64]. [ $\left.\mathrm{AuCl}\left(\mathrm{PPh}_{3}\right)\right] / \mathrm{AgOTf}$ was the catalyst system of choice and the reaction was, depending on the substrate, performed under thermal or microwave-assisted conditions. The wide range of alkene substrates and the low catalyst amounts render this method a highly efficient and convenient synthesis of 3 -functionalized indole derivatives (Scheme 19). 


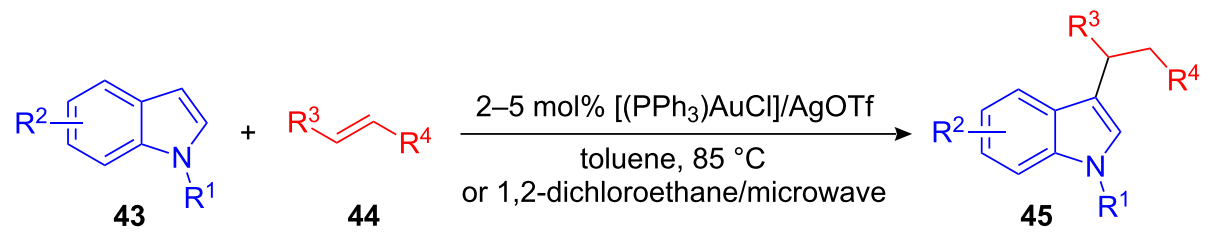

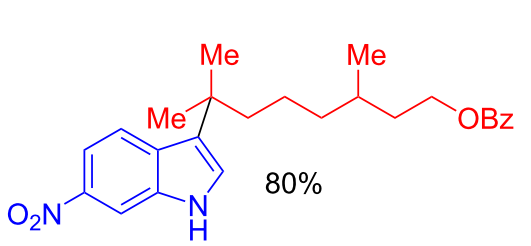<smiles></smiles><smiles>CC(c1ccc(N(C)C)cc1)c1cn(C)c2ccccc12</smiles><smiles>CCOC(=O)CC(C)CCCC(C)(C)c1cn(-c2ccccc2)c2ccccc12</smiles><smiles>O=[N+]([O-])c1c[nH]c2c(C3CC=CCC3)cccc12</smiles>

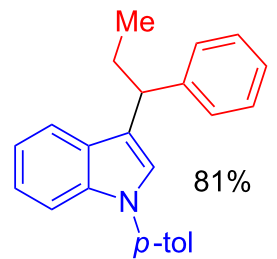

Scheme 19: $\mathrm{Au}(\mathrm{I}) / \mathrm{Ag}(\mathrm{I})$-catalyzed hydroarylation of indoles with styrenes, aliphatic and cyclic alkenes.

An elegant $\mathrm{PtCl}_{2}$-catalyzed intramolecular alkylation of indoles with inactivated alkenes has been developed by Widenhoefer et al. [65]. In addition to the transition metal $\mathrm{Pt}(\mathrm{II})$, catalytic amounts of hydrochloric acid were necessary to obtain the desired 2,3-annulated indoles in sufficient yields. By employing optically pure axial chiral phosphane ligands, an enantioselective version of this transformation was developed which provided the products with high enantioselectivities.

Beside indoles, anilines have gained much attention as target for hydroarylation reactions. However, the main issues for FC alkylations of anilines are the deactivation of the catalyst due to coordination of the primary amine and/or concurrent hydroamination reactions [66]. Nevertheless, Beller et al. developed a valuable method to overcome these limitations. In 1999 they described the transition metal catalyzed hydroarylation of anilines 46 with styrenes using a cationic Rh-complex [67]. Depending on the aniline derivative, a combination of $2.5 \mathrm{~mol} \%$ $\left[\mathrm{Rh}(\mathrm{cod})_{2}\right] \mathrm{BF}_{4}, 4 \mathrm{~mol} \% \mathrm{PPh}_{3}$ and $\mathrm{HBF}_{4} \cdot \mathrm{OEt}_{2}$ was necessary for sufficient reactivity; yet electron-rich and $\mathrm{N}$-alkylated anilines react without a metal catalysis in the presence of catalytic amounts of $\mathrm{HBF}_{4}$ (Scheme 20). About the same time a $\mathrm{Ru}_{3}(\mathrm{CO})_{12}$-catalyzed hydroarylation of anilines was reported as well [68].

Ackermann et al. attempted to develop a Ti(IV)-catalyzed hydroamination of anilines with olefins, and surprisingly discovered that a mixture of hydroamination and orthohydroarylation products was formed. Upon further heating of the secondary amine 48 in the presence of $\mathrm{TiCl}_{4}$ the orthoarylated aniline 49 was formed quantitatively (Scheme 21A). Reaction conditions were improved and with $20 \mathrm{~mol}^{\%}$ of $\mathrm{TiCl}_{4}$ a variety of electron-rich and electron-poor anilines $\mathbf{5 1}$ and styrenes $\mathbf{5 0}$ were utilized for giving diverse ortho-benzylated anilines $\mathbf{5 2}$ in moderate to good yields (Scheme 21B) [69].

Almost simultaneously, an acid-catalyzed ortho-arylation of aniline employing the strong Brønsted acid $\mathrm{PhNH}_{3} \mathrm{~B}\left(\mathrm{C}_{6} \mathrm{~F}_{5}\right)_{4} \cdot \mathrm{Et}_{2} \mathrm{O}$ was developed by Bergman et al. indicating the close relationship between strong Brønsted acid- and transition-metal catalysis [70].

A double ortho-hydroarylation of anilines with styrenes was presented by Coates and co-workers giving a mixture of $\mathbf{5 3}$ and ent-53 and the corresponding meso compound. In combination with enantioselective separation techniques, such as HPLC, or

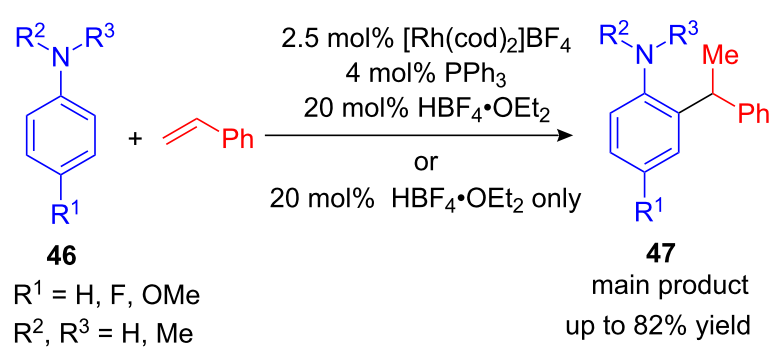

Scheme 20: First transition-metal-catalyzed ortho-hydroarylation developed by Beller et al. 
A

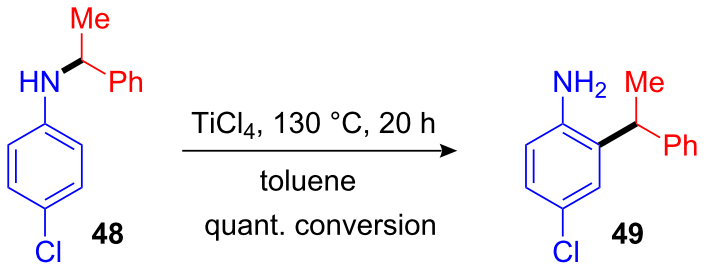

B

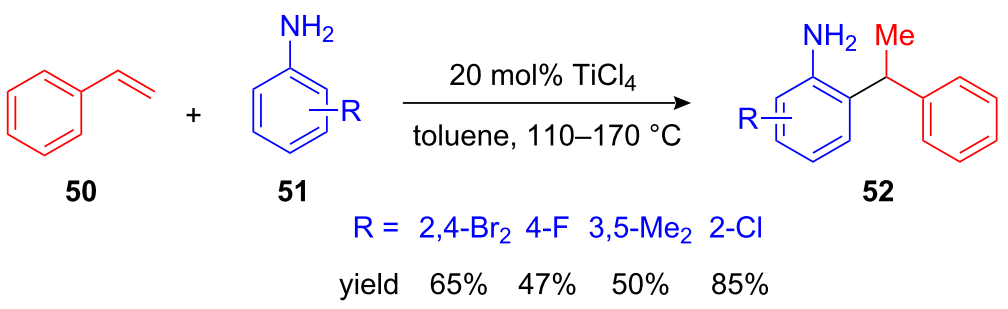

Scheme 21: (A) Ti(IV)-mediated rearrangement of an N-benzylated aniline to the corresponding ortho-alkylated aniline. (B) ortho-Arylation of anilines with styrenes in the presence of $\mathrm{TiCl}_{4}$.

upon resolution with chiral Brønsted acids this method provides valuable ortho-chiral anilines that could be used as valuable optical active ligands for enantioselective transition-metal catalysis (Scheme 22) [71].

To the best of our knowledge, efficient ortho-benzylations of anilines with benzyl alcohols as alkylating reagents have yet to be described [15].

\section{Catalytic Friedel-Crafts allylations}

Allylated arenes represent attractive precursors for organic synthesis as there are several possibilities for further transforming the exocyclic double bonds. Typically, in transition-metal-catalyzed allylation reactions reactive, metal-coordinated allyl cations are formed which may lead to linear and branched products, whereby the product ratio is dependent on the catalyst employed (Scheme 23). To date, only few FC-type allyla-

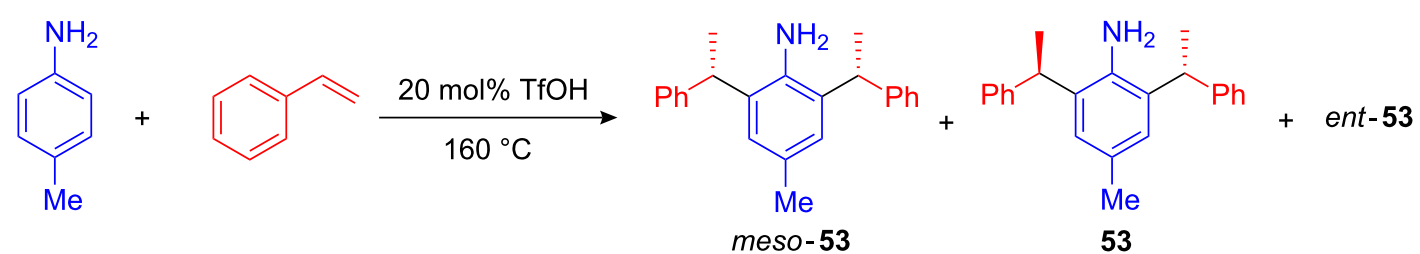

Scheme 22: Dibenzylation of aniline gives potentially useful amine-based ligands in a one-step procedure.

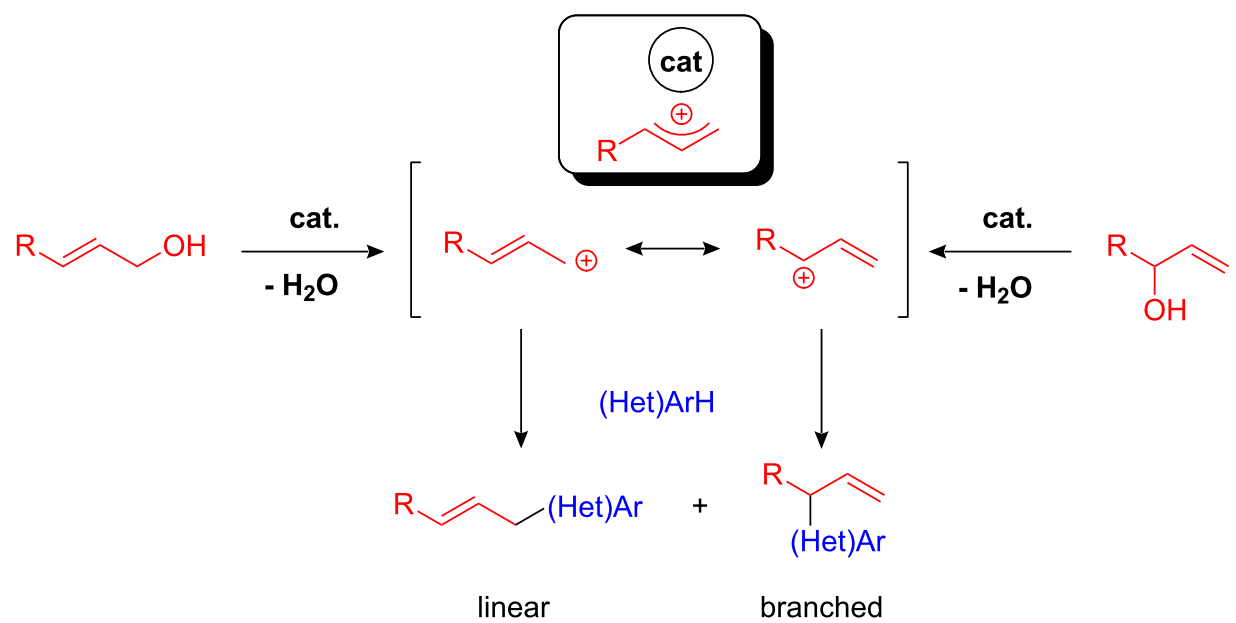

Scheme 23: FC-type alkylations with allyl alcohols as alkylating reagents - linear vs. branched product formation. 


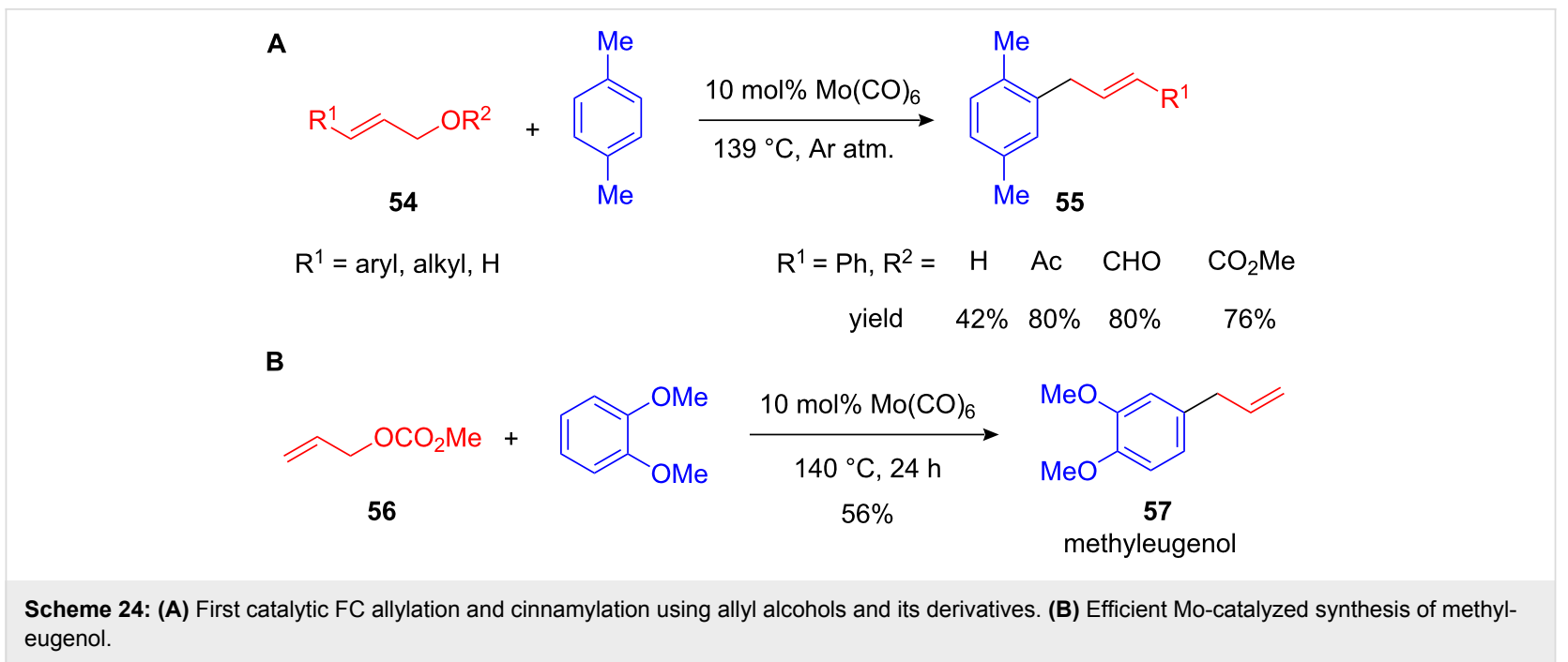

tions with environmentally benign allylating reagents, such as allyl alcohols have been reported.

Here Shimizu and co-workers did seminal work by developing a $\mathrm{Mo}(\mathrm{CO})_{6^{-}}$and $\mathrm{W}(\mathrm{CO})_{6}$-catalyzed allylation and cinnamylation of electron-rich arenes. Employing, for instance, $p$-xylene or toluene and cinnamyl alcohols or -carbonates $\mathbf{5 4}$ in the presence of $10 \mathrm{~mol} \%$ of $\mathrm{Mo}(\mathrm{CO})_{6}$ the desired allylated arenes $\mathbf{5 5}$ could be isolated in good yields (Scheme 24A) [72]. As application of this methodology, methyleugenol 57, an ingredient in many spices and essential oils, could be synthesized in one step starting from allyl carbonate 56 and 1,2-dimethoxybenzene (Scheme 24B). A similar method using a diruthenium complex was developed by Hidai and co-workers [73]. The reaction conditions of both methods were still harsh and the use of $\mathrm{Mo}(\mathrm{CO})_{6}$ as a catalyst required exclusion of air and moisture. Moreover, the reactive allyl carbonates or acetates had to be applied due to the easier activation as better leaving groups. Hence, improved procedures with less sensitive and cheaper catalysts as well as unprotected alcohols had to be developed.

One of the first examples of a catalytic FC alkylation of arenes with unprotected allyl- and cinnamyl alcohols was developed by Kočovský et al. in 1999 [74,75]. Employing small amounts of a
Mo(IV)-complex, allyl alcohols could be substituted with electron-rich arenes such as phenol and anisol. Interestingly, the application of the in situ generated Mo(IV)-catalyst $\mathrm{Mo}(\mathrm{acac})_{2}\left(\mathrm{SbF}_{6}\right)_{2}$ resulted exclusively in $C$-allylated arenes, while the catalyst precursor $\mathrm{Mo}(\mathrm{acac})_{2} \mathrm{Cl}_{2}$ gave the $O$-allylated phenols as major products. Remarkably the reaction between $p$-cresol 58 and linear or branched allyl alcohols 54a or 54b did not give the corresponding alkylated cresol 59. Instead the chromane 60 was observed in 28\% yield (Scheme 25). This reaction has recently been improved and extended by applying $\mathrm{MoCl}(\mathrm{CO})_{3} \mathrm{Cp}$ and $\left[\mathrm{Mo}(\mathrm{CO})_{3} \mathrm{Cp}\right]_{2}$ as transition-metal catalysts [76].

A very similar FC allylation/hydroaralyation reaction was subsequently used by other groups for the synthesis of (all-rac)$\alpha$-tocopherol 63 (Vitamin E) and its more stable acetate derivative starting from the two precursors trimethylhydroquinone 61 and isophytol 62 [77-79]. Strong Brønsted acids as well as various rare-earth metal triflates and silicon-based Lewis acids were used as catalysts (Scheme 26).

Chan and co-workers developed an efficient $\mathrm{Au}(\mathrm{III})$-catalyzed FC arylation of cinnamyl alcohols 64 and electron-rich arenes such as 2,6-dimethylphenol $\mathbf{6 5}$. The authors found that this

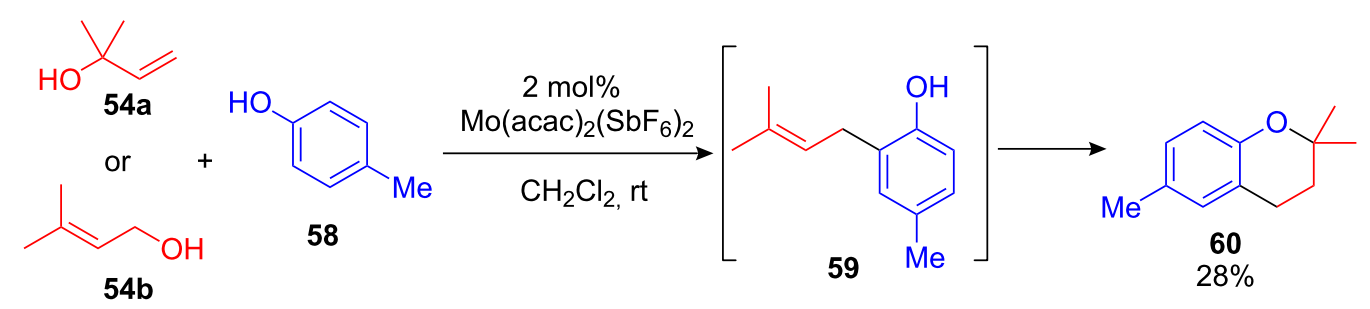

Scheme 25: FC allylation/cyclization reaction yielding substituted chromanes. 


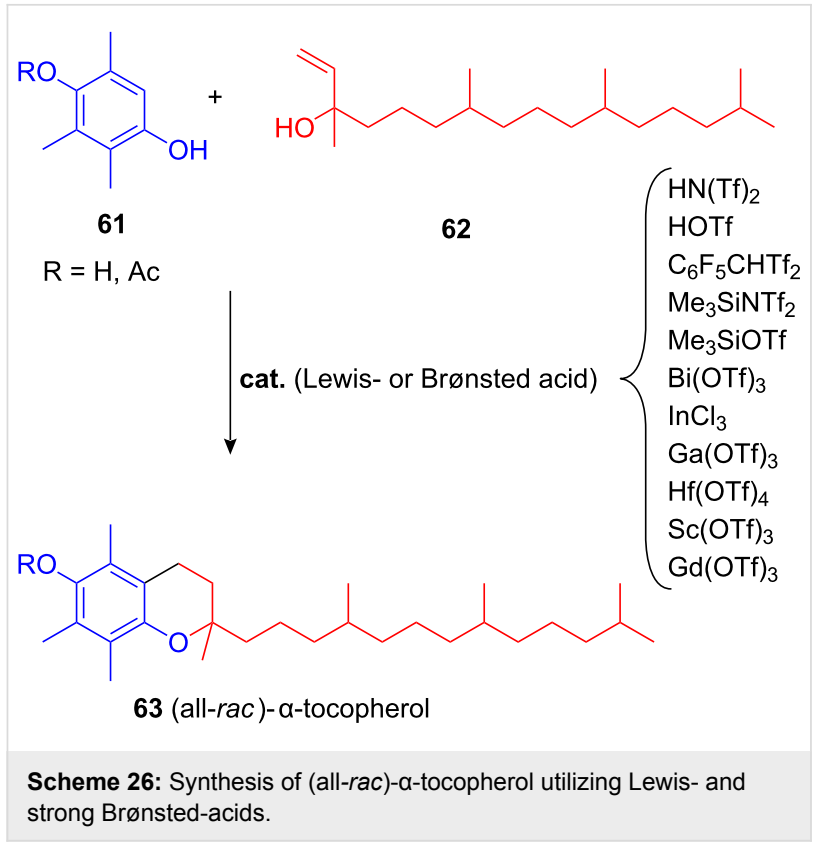

Scheme 26: Synthesis of (all-rac)- $\alpha$-tocopherol utilizing Lewis- and strong Brønsted-acids. transformation can be catalyzed by various transition metals and Brønsted acids, including $\mathrm{Au}(\mathrm{III}), \mathrm{Ag}(\mathrm{I}), \mathrm{In}(\mathrm{III}), \mathrm{Zn}(\mathrm{II}), \mathrm{Cu}(\mathrm{II})$ salts or sulfonic acids. $\mathrm{AuCl}_{3}$ was the most reactive and was subsequently used for further studies. With $5 \mathrm{~mol} \%$ of catalyst and performing the reaction at room temperature, the desired allylated arenes and heteroarenes 66 were isolated in good yields after short reaction times. Beside cinnamyl alcohols 66a and $\mathbf{6 6}$ b, 1-arylated allyl alcohols could be used in this transformation giving, for example, the benzylated dihydronaphthalene 66c and cyclohexanone 66d in good yield (Scheme 27) [80].

As a curiosity, Tamaru et al. reported an "exhaustive" $\operatorname{Pd}(0)$ catalyzed allylation of benzene-1,3,5-triol (67), resulting in the highly allylated cyclohexane-1,3,5-trione 69 in high yields. This structure is expected to be a useful precursor for supramolecular architectures with $C_{3}$ symmetry (Scheme 28) [81].<smiles>[R]C=CC([R])c1cc([N+](=O)[O-])c(O)c([N+](=O)[O-])c1</smiles>

64

65

66

Product ( $\mathrm{Ar}=4-\mathrm{OH}-$ $\left.3,5-(\mathrm{Me})_{2}-\mathrm{Ph}\right)$<smiles>CC(Br)/C=C/c1ccccc1</smiles>

$66 a$

$97 \%$<smiles>BrC/C=C/c1ccc(Br)cc1</smiles>

$66 \mathrm{~b}$

$80 \%$<smiles>Cc1ccc(C(C2=Cc3ccccc3CC2)C2CCCCC2)cc1</smiles>

$66 \mathrm{c}$

$77 \%$<smiles>O=C1CCCC=C1C(Br)c1ccccc1</smiles>

$66 \mathrm{~d}$

$98 \%$

Scheme 27: $\mathrm{Au}(\mathrm{III})$-catalyzed cinnamylation of arenes.

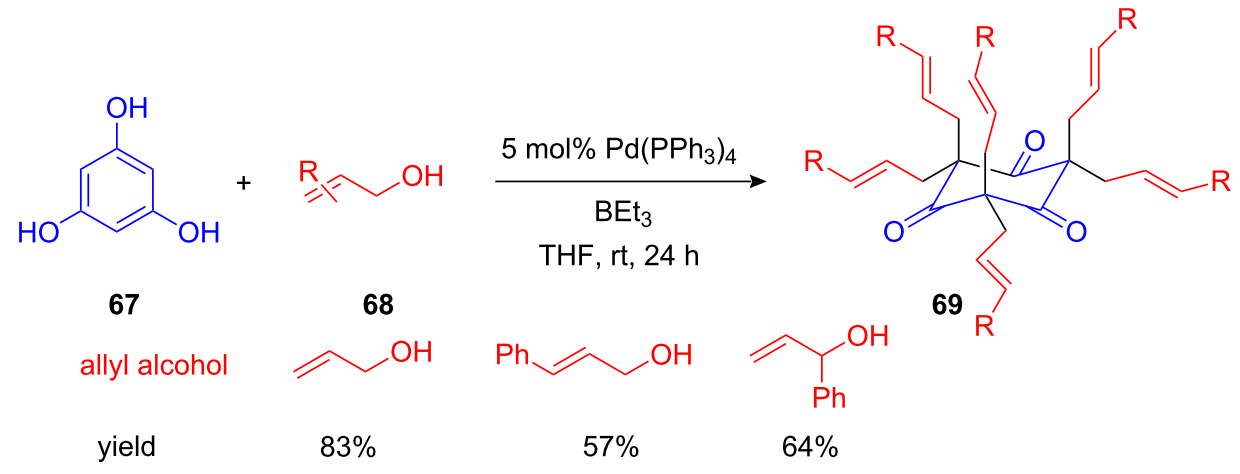


<smiles></smiles>

70<smiles>C=CCc1c[nH]c2ccc([N+](=O)[O-])cc12</smiles>

yield
71<smiles>C=CCc1c[nH]c2ccc(O)cc12</smiles>

$96 \%$

72<smiles>C=CCc1c[nH]c2cccc(Br)c12</smiles>

$84 \%$<smiles>C=CCC1(C)C=Nc2ccccc21</smiles>

$75 \%$

Scheme 29: Palladium-catalyzed allylation of indole.

It is worth mentioning that in this example as well as in the following Pd-catalyzed allylations an intermediary electrophilic Pd-allyl complex as the reactive allylating species is more likely than the formation of a free allyl cation.

The indole core structure is widely distributed in natural occurring and biologically active molecules and hence, its allylation is of great interest for organic synthesis. It is surprising that it took over eight years from the first description of catalytic allylations of arenes by Shimizu until the first catalytic allylation of indole was described. Here, a combination of $\mathrm{Et}_{3} \mathrm{~B}$ and $\operatorname{Pd}(0)$ led to an efficient C3-selective allylation [82]. Employing free allyl alcohols and a combination of $5 \mathrm{~mol} \%$ of $\mathrm{Pd}\left(\mathrm{PPh}_{3}\right)_{4}$ and $30 \mathrm{~mol} \%$ triethylborane as catalyst, the desired 3-allylated indoles were isolated in excellent yields (Scheme 29). Electron withdrawing as well as electron donating groups were well tolerated. Other allylating reagents, such as $\beta$-methyl-, $\alpha, \alpha-$, and $\gamma, \gamma$-dimethylallyl alcohols or cinnamyl alcohol could also be used in this reaction.

Additionally, high selectivity towards the linear allylated indoles was observed. Surprisingly, $N$-allylation did not occur. With L-tryptophan methyl ester (73) as the indole moiety, this method led to a convenient stereoselective synthesis of a highly substituted pyrroloindole framework 74 (Scheme 30); however, equimolar amounts of triethylborane were necessary.

An improved FC allylation of indoles with allyl alcohols was developed recently by Breit et al. using self-assembling palladium-phosphane catalysts [83]. Further procedures for the 3-benzylation and allylation of indole employing $\mathrm{FeCl}_{3}$ and $\mathrm{InBr}_{3}$ have been developed more recently by Yadav and Jana $[84,85]$. Both procedures are very similar and employ $10 \mathrm{~mol} \%$ of catalyst. However, the reaction with $\mathrm{InBr}_{3}$ can be performed at room temperature, which may be due to the higher Lewis acidity.

While the catalysts described above gave primarily linear allylation products, procedures that would give branched allylated arenes would be even more desirable. An example of such a transformation was recently uncovered by Pregosin and co-workers. The cationic Trost-type Ru(IV)-sulfonate catalyst 77 gives high regioselectivity for branched allylated arenes. As electron-rich arenes, pyrroles 75 and indole (76) can be utilized (Scheme 31) [86]. Interestingly, the addition of sulfonic acid was crucial for the high reactivity and the observed regioselectivity $[87,88]$. Branched/linear ratios of the desired products 78 and 79 were found to range between $2.3: 1$ and $100: 0$. The

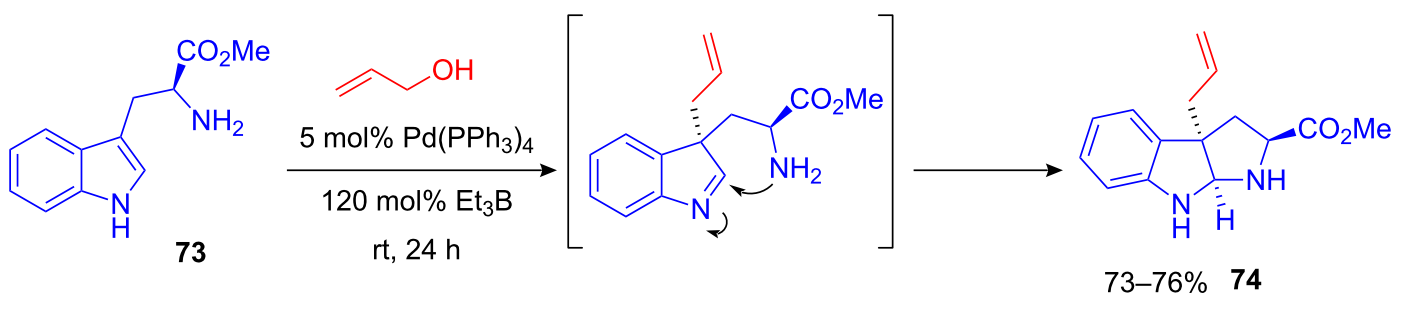

endo isomer 


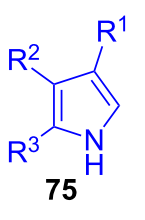

or<smiles>c1ccc2[nH]ccc2c1</smiles>

76

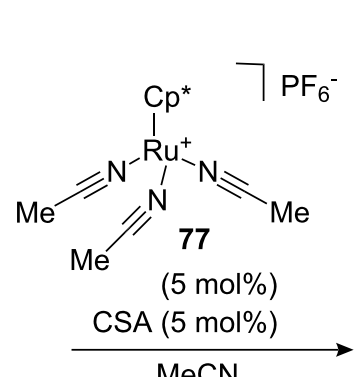

MeCN

5-50 min.

$\mathrm{R}^{4} \curvearrowright \mathrm{OH}$ linear<smiles>[R4]C=CCc1[nH]c([R3])c([R])c1[R]</smiles>

$\mathbf{7 8 a} b / / 12: 1$ to $100: 0 \mathbf{7 9 a}$<smiles>[R4]C=CCc1c[nH]c2ccccc12</smiles>

$78 b \quad b / l 2.3: 1$ to $49: 179 b$

Scheme 31: Ru(IV)-catalyzed allylation of indole and pyrroles with unique regioselectivity.

selectivity of this reaction is thought to be driven by the LUMO of the $\mathrm{Ru}(\mathrm{IV})$-allyl complex intermediate.

Besides intermolecular allylations, intramolecular FC-type allylations are of great importance. One of the first intramolecular FC-type transformations using allyl alcohols was developed by Nishizawa et al. using $\operatorname{Hg}(\mathrm{OTf})_{2}$ as Lewis acid [89]. Since $\mathrm{Hg}(\mathrm{II})$ is not an environmentally friendly transition metal, Bandini et al. developed a "greener" Ag(I)- and Mo(II)catalyzed variant (Scheme 32) [90,91]. The desired tetrahydronaphthalenes $\mathbf{8 1}$ were obtained in high yields under ambient reaction conditions (Scheme 32) [91]. Subsequently a very similar iron(III)-catalyzed intramolecular FC alkylation of propargyl alcohols was developed by Zhou et al. Depending on the reaction conditions one observes either the corresponding dihydronaphthalenes or allenes as the main reaction products [92].

\section{Catalytic propargylation of arenes}

(Prop-2-ynyl)arenes $\mathbf{8 4}$ are widely distributed structural motifs in organic chemistry due to the high synthetic value of the alkyne functionality. This makes them suitable precursors for the synthesis of highly substituted 1,1-diarylalkanes. Thus efficient routes to this important core structure are constantly needed. One of the most efficient ways for synthesising (prop2 -ynyl)arenes is the direct propargylation of arenes and heteroarenes with propargyl alcohols. This reaction is typically more difficult to achieve since the intermediary propargyl cations 83a are in equilibrium with the corresponding $\mathrm{sp}^{2}$ hybridized allenylium cations $\mathbf{8 3 \mathbf { b }}$ and the latter are prone to undergo polymerization or side reactions, such as $\gamma$-substitution (Scheme 33).

So far the Nicholas reaction has been the method of choice for the propargylation of aromatic systems. However the use of

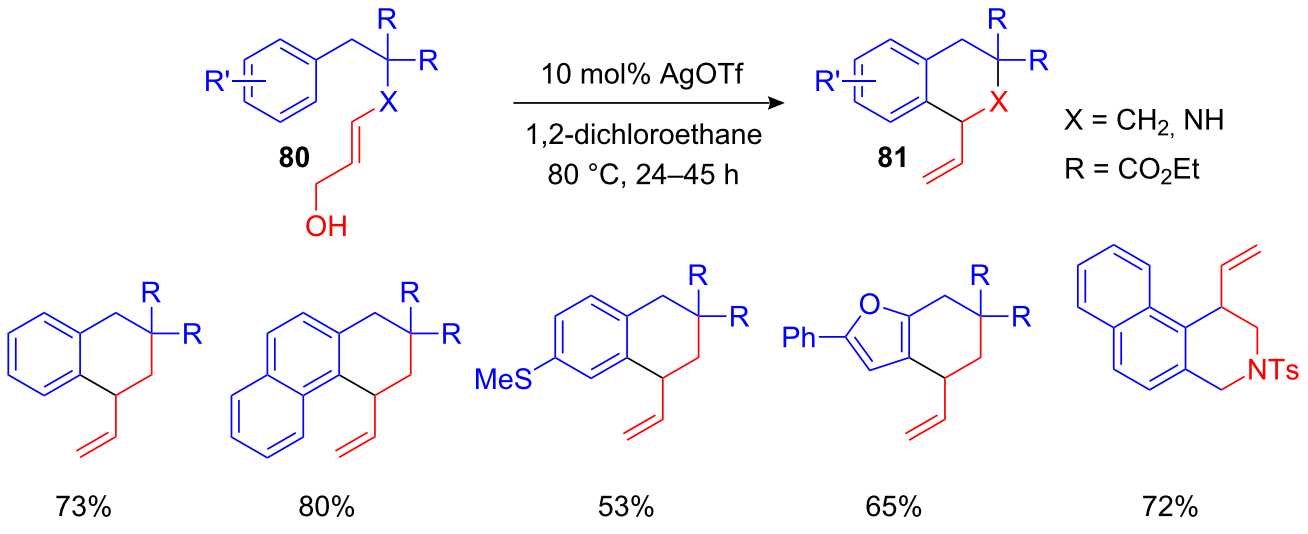




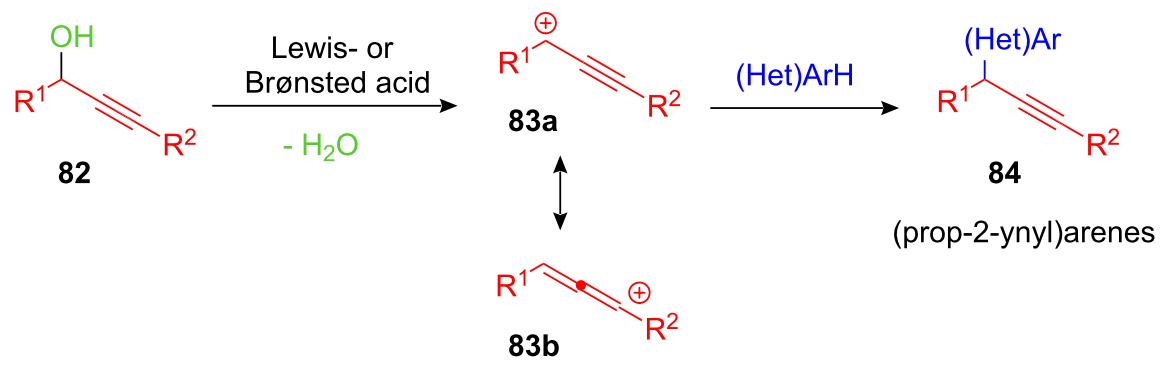

Scheme 33: FC-type alkylations of arenes using propargyl alcohols.

stoichiometric amounts of $\mathrm{Co}_{2}(\mathrm{CO})_{8}$ and oxidation reagents denotes a fairly inefficient transformation [93].

Uemura and co-workers discovered in 2002 that heating stoichiometric amounts of a cationic Ru-allenylidene complex 86, which has been synthesised from the Ru-precursor 85a, together with 10 equiv of 2-methylfuran led to rapid formation of 5-propargylated 2-methylfuran 87 in 34\% yield (Scheme 34A) [94]. Subsequently a catalytic variant of this transformation was developed by using diruthenium complexes 85a and $\mathbf{8 5} \mathbf{b}$ (Scheme 34B) [95]. The reaction proceeded smoothly and yields of the propargylated arenes $\mathbf{8 9}$ were even higher when only small amounts of the catalyst were used.
Interestingly, if phenols and naphthols 91 were applied as nucleophiles, both $\mathrm{C}_{\alpha^{-}}$and $\mathrm{C}_{\gamma^{-}}$-carbon atoms of allenylidene- $\mathrm{Ru}$ 92 complex were attacked giving rise to the corresponding chromenes and 1-substituted $1 H$-naphtho[2,1-b]pyrans 93, respectively, in moderate to excellent yields (Scheme 35). Electron-withdrawing as well as electron-donating functional groups were tolerated on the phenol scaffold, whereas 1,1-diarylsubstituted propargylic alcohols did not react at all [96]. The same authors expanded their procedure to an enantioselective propargylation of arenes using a chiral Ru-complex [97]. This outstanding transformation is discussed in more detail in the following chapter of this review.
A

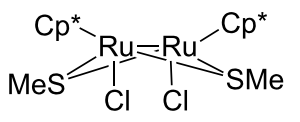
$85 a$<smiles>C#CC(O)c1ccccc1</smiles>

$30 \mathrm{~min}, \mathrm{rt}$

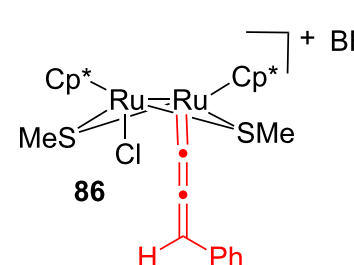<smiles>Cc1ccc(C(F)(F)F)o1</smiles>

$60{ }^{\circ} \mathrm{C}, 6 \mathrm{~h}$<smiles>C#CC(c1ccccc1)c1ccc(C)o1</smiles>

B<smiles>OC(C#Cc1ccccc1)c1ccccc1</smiles>

88

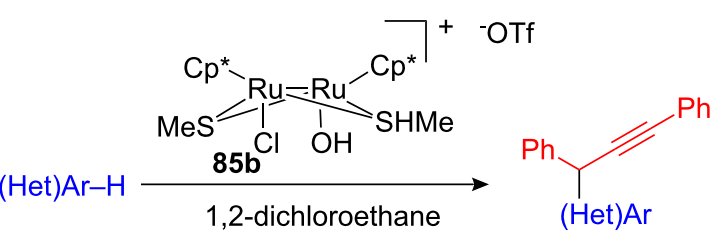

$60{ }^{\circ} \mathrm{C}, 1-25 \mathrm{~h}$

89<smiles>COc1cc(NC(C)=O)cc(NC(C)=O)c1</smiles> 


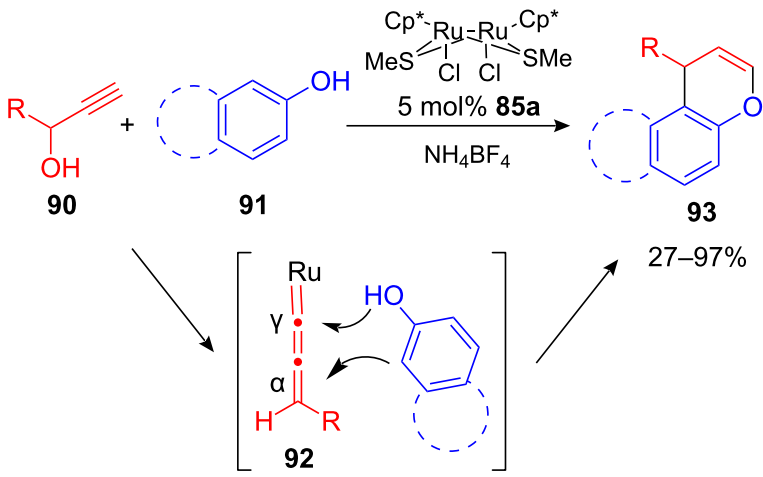

Scheme 35: Diruthenium-catalyzed formation of chromenes and $1 H$-naphtho[2,1-b]pyrans.

A related cationic Ru-vinylidene complex was used for an efficient alkynylation of pyridines with (alkyn-1-yl)trimethylsilane [98].

Based on these preliminary results, various catalytic propargylations of arenes have been developed, employing catalysts such as Mo/chloranil [16], polymolybdophosphoric acid supported silica [99], TsOH [100], $\mathrm{FeCl}_{3}$ [101,102], $\mathrm{BiCl}_{3}$ [103], $\mathrm{Sc}(\mathrm{OTf})_{3}$ [104] other Ru- or [105-107], Re-complexes [108] and even molecular iodine [109].
Toste and co-workers developed a mild rhenium-catalyzed propargylation of electron-rich arenes. In addition to principal method development, the authors applied their procedure towards the synthesis of several biologically active molecules. Starting from ethyl propiolate 95 and safrole 94, the desired FC alkylation product 96 was isolated in $66 \%$ yield. A subsequent six-step synthesis yielded $\beta$-apopicropodophyllin (97), a previously described precursor of cyctotoxic aryltetralinlactone podophyllotoxin (98; Scheme 36) [108].

Likewise, the two natural occurring benzhydryl compounds mimosifoliol 99 and $O$-methyldetrol 100 were obtained from readily available arenes and propargyl alcohols. The FC propargylations that were necessary in the first step were carried out in the presence of air and moisture with just $5 \mathrm{~mol} \%$ $\mathrm{Re}(\mathrm{O})(\mathrm{dppm}) \mathrm{Cl}_{3}$ and $5 \mathrm{~mol} \%$ potassium or silver hexafluoridophosphate as a halide abstractor. Remarkably, $\gamma$-heteroatom substituted propargyl alcohols can also be used as alkylating reagent.

Yoshimatsu et al. developed a scandium-catalyzed FC alkylation using 3-sulfanyl- and 3-selanylpropargylic alcohols 101. With $5 \mathrm{~mol} \%$ of $\mathrm{Sc}(\mathrm{OTf})_{3}$ as the catalyst and a surprisingly low reaction temperature $\left(0{ }^{\circ} \mathrm{C}\right)$ the desired propargylated arenes 102 were isolated in good to high yields. Beside arenes and heteroarenes, allylsilane and vinyl silyl ethers were used as<smiles>C=CCc1ccc2c(c1)OCO2</smiles>

94<smiles>C=CC(c1ccccc1)c1cc(OC)c(O)cc1OC</smiles>

mimosifoliol<smiles>COc1ccc(C)cc1[C@H](CCN(C(C)C)C(C)C)c1ccccc1</smiles>

100<smiles>C=CCc1cc2c(cc1C(C#CC(=O)OCC)c1cc(OC)c(OC)c(OC)c1)OCO2</smiles>

95

$\mathrm{MeNO}_{2}, 50^{\circ} \mathrm{C}$

$66 \% 96$<smiles>C=CC(C)C</smiles>

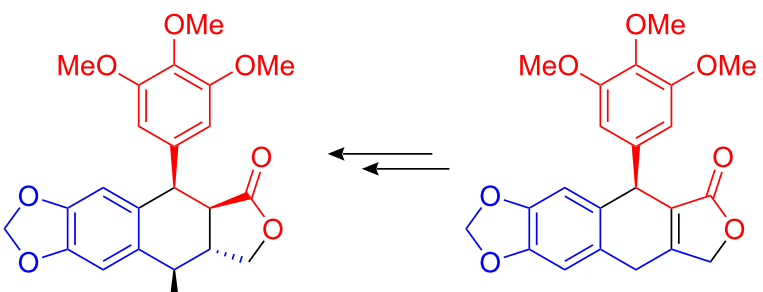

98

podophyllotoxin
97

B-apopicropodophyllin

$O$-methyldetrol

Scheme 36: Rhenium(V)-catalyzed FC propargylations as a first step in the total synthesis of podophyllotoxin, mimosifoliol and O-methyldetrol. 


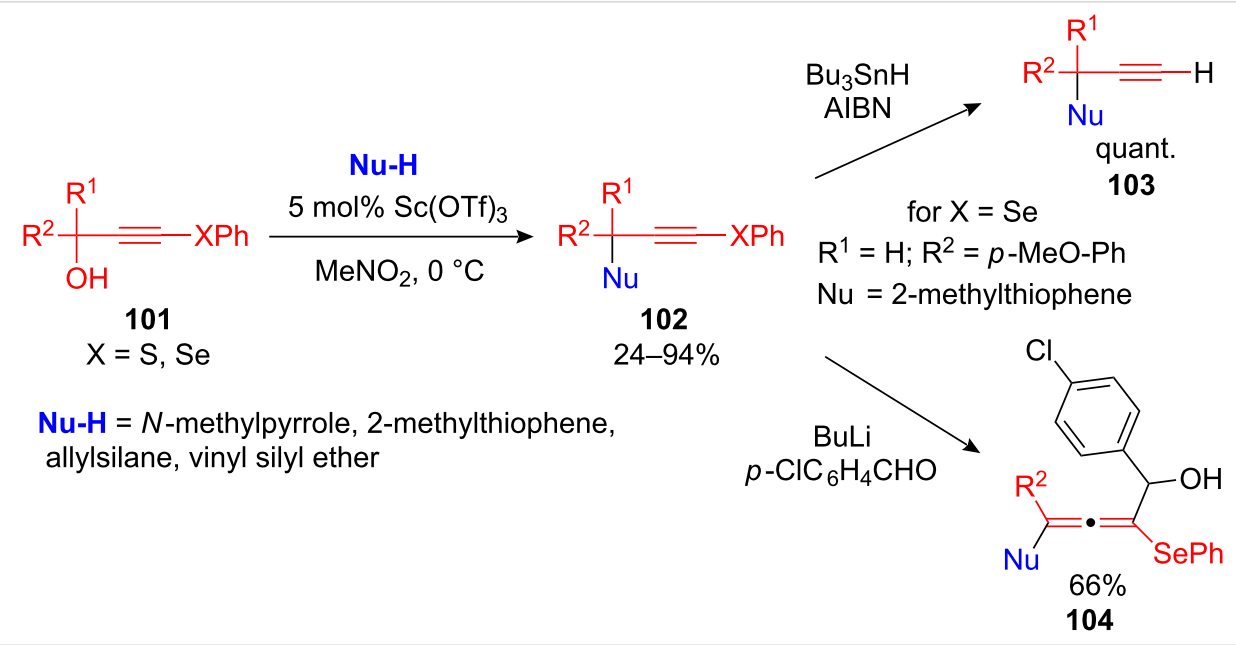

Scheme 37: Scandium-catalyzed arylation of 3-sulfanyl- and 3-selanylpropargyl alcohols.

nucleophiles in this transformation [110]. The substituted $\gamma$-selenopropargyl compounds were readily transformed into the terminal alkynes $\mathbf{1 0 3}$ by treatment with tributyltin hydride or were further functionalized with aldehydes to form the highly substituted allenyl alcohols 104 (Scheme 37).

While the methods described above used $\alpha$-arylated propargyl alcohols as highly reactive alkylating reagents, reports of the arylation of $\alpha$-unsubstituted propargyl groups are few. In these reactions the alcohol has to be activated as a leaving group in order to obtain sufficient reactivity. One example utilizing the propargyl trichloracetimidates $\mathbf{1 0 5}$ was described recently by Wang and co-workers. With $30 \mathrm{~mol} \%$ of boron trifluoride etherate, the highly desired 1,3-diarylpropynes $\mathbf{1 0 6}$ were

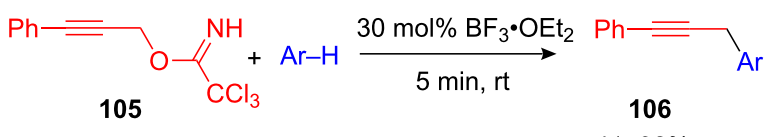

$$
\begin{aligned}
& 41-92 \%
\end{aligned}
$$

Scheme 38: Synthesis of 1,3-diarylpropynes via direct coupling of propargyl trichloracetimidates and arenes. obtained in good yields. The reaction was over within $5 \mathrm{~min}$ and various arenes and heteroarenes, including toluene, xylene, thiophene or furan were tolerated as nucleophiles (Scheme 38) [111].

\section{Catalytic enantioselective and diastereose- lective Friedel-Crafts alkylations}

Despite the recent effort in the development of FC alkylations, enantio- and diastereoselective FC alkylations using chiral alcohol precursors are rare. Due to the fact that Lewis- or Brønsted-acid-catalyzed FC alkylations are passing through a carbocationic intermediate, the alcohol itself can not be used as the chiral precursor (Scheme 39). In order to circumvent this problem, benzyl alcohols with a stereocenter in the $\alpha$-position were employed as directing groups.

This approach was used by Bach and co-workers employing the $\alpha$-tert-butyl-substituted benzyl alcohol 107 (Scheme 40A). Various electron-rich arenes and heteroarenes were applied giving rise to chiral arenes $\mathbf{1 0 8}$ with remarkable syn-diastereoselectivities of up to $94: 6$ d.r. $[112,113]$. Beside the tertbutyl moiety as regio-discriminating group, other useful

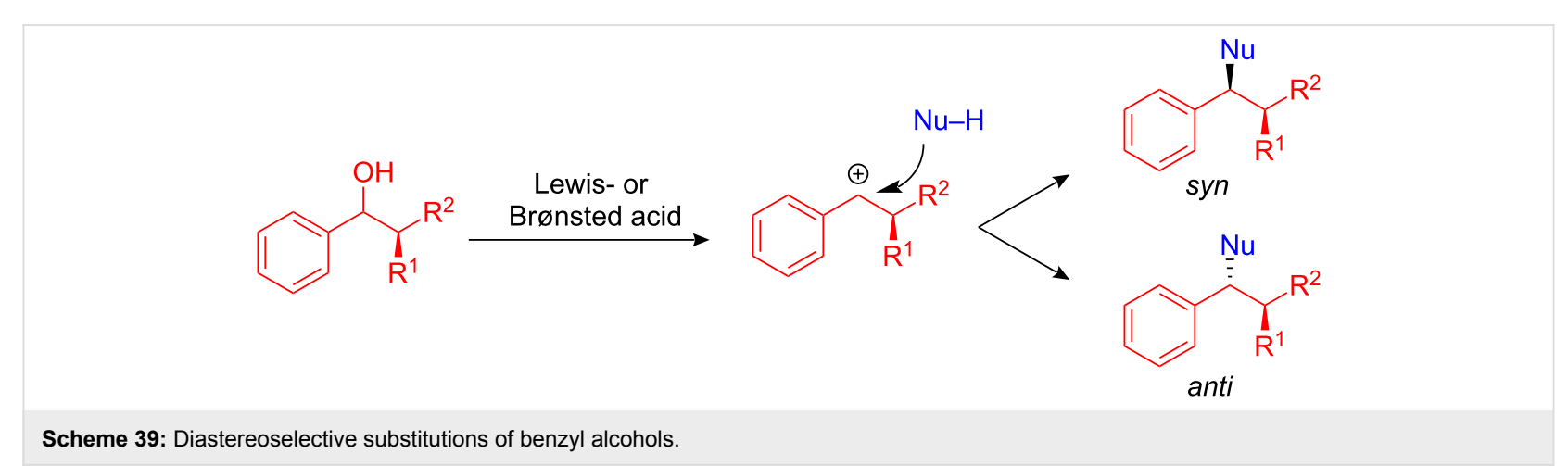




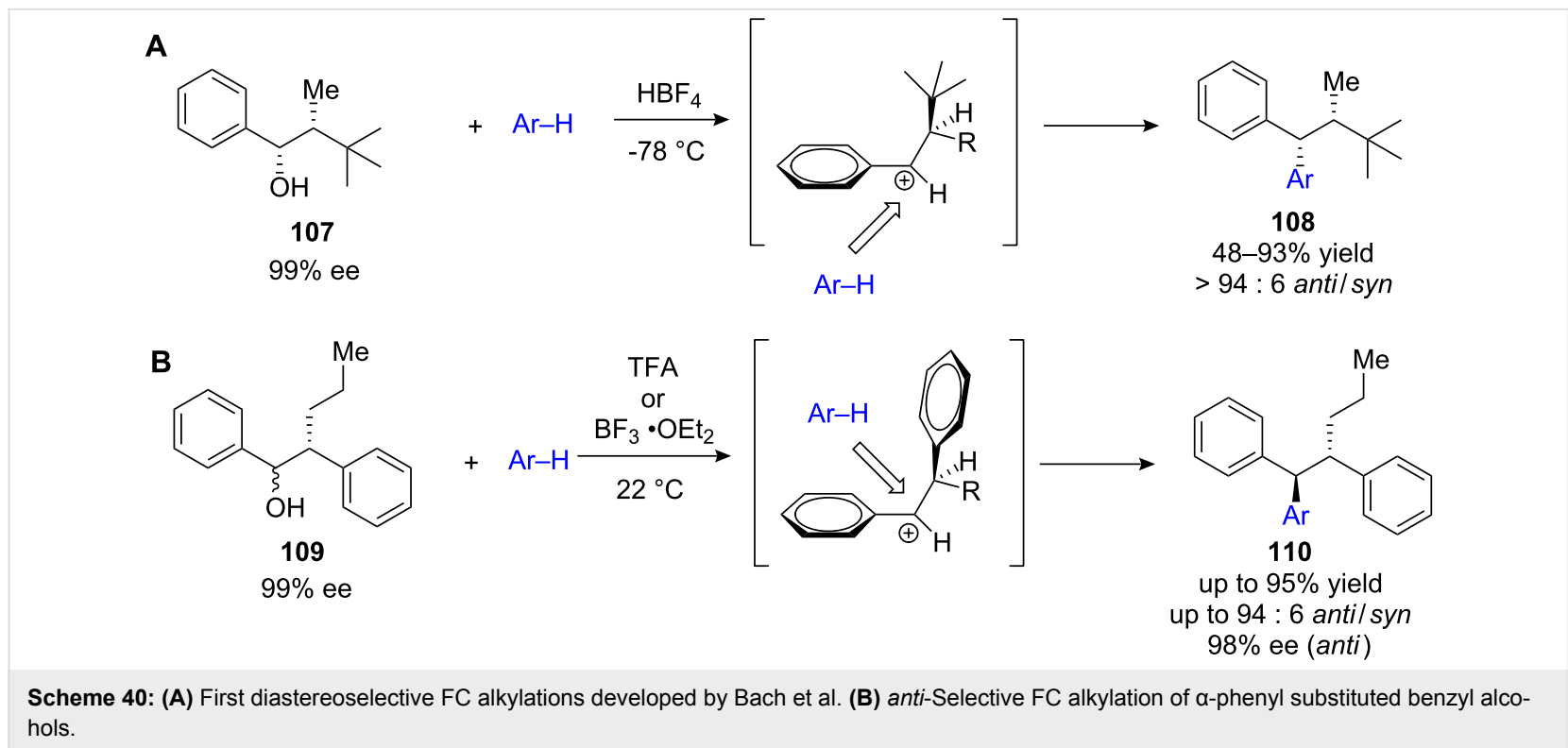

synthetic functional groups such as nitro-, cyano- or hydroxy functionalities could effectively be used [114]. Enantiomerically enriched benzyl alcohols did not lose their stereochemical information during substitution. In addition both, syn- and anti diastereoisomer of the starting material gave the $s y n$-configured products as the major diastereoisomer. This strongly indicates a carbocation as reaction intermediate and rules out an $\mathrm{S}_{\mathrm{N}} 1$-type reaction mechanism. Additionally, low temperature NMR studies in superacidic media clearly profed the carbocationic character of the benzylic carbon atom [113].

When the tert-butyl-group is replaced by phenyl functionalities 109, a reverse in diastereoselectivity is observed. This may be a result of $\Pi$-stacking interactions [115]. Again, various arenes and heteroarenes, including indoles, thiophenes, pyrroles or furans gave the desired anti-1,1,2-triarylalkanes 110 in good yields and with high diastereoselectivities (Scheme 40B). $\mathrm{BF}_{3} \cdot \mathrm{OEt}_{2}$ and TFA were used in stoichiometric amounts to promote this reaction. However, application of $\mathrm{BF}_{3}$ resulted in significantly higher reactivity, while the diastereoselectivity was higher when TFA was used. The enantiomeric excess did not significantly diminish during this procedure, which makes this reaction a convenient and efficient route to optically pure 1,1,2triarylalkanes.

A drawback of this first diastereoselective FC alkylation of chiral benzyl alcohols was the necessity for stoichiometric amounts $\mathrm{HBF}_{4}$ and low temperatures in order to observe high diastereoselectivities. To overcome these drawbacks, Bach et al. developed an efficient $\mathrm{AuCl}_{3}$-catalyzed arylation of benzyl alcohols and acetates with chiral phenylbutanoates 111 [116]. In addition to arenes and heteroarenes, other nucleophiles including allylsilane, tosylamine, TMS-cyanide, acetylacetonates and silyl enol ethers were successfully used as nucleophilic components giving the substituted 3-phenylbutanoates 112 in high yields and with excellent diastereoselectivities (Scheme 41). The reaction could be performed at ambient temperatures and in sharp contrast to the previous described $\mathrm{HBF}_{4}-$ mediated procedure, high anti-selectivity was observed in the formation of $\mathbf{1 1 2}$.<smiles>COc1ccc(C(OC(C)=O)C(C)C(C)OC(C)=O)cc1</smiles>

111

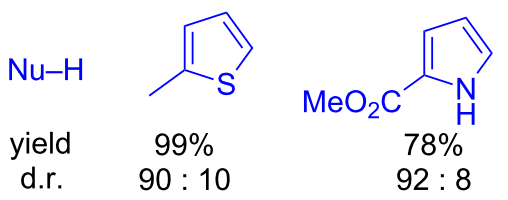<smiles>c1ccc2occc2c1</smiles>

$99 \%$

$90: 10$<smiles>CC(=O)CC(C)=O</smiles>

TMS-CN $\mathrm{Ts}-\mathrm{NH}_{2}$

$77 \%$

$91: 9$

Scheme 41: Diastereoselective $\mathrm{AuCl}_{3}$-catalyzed FC alkylation. 


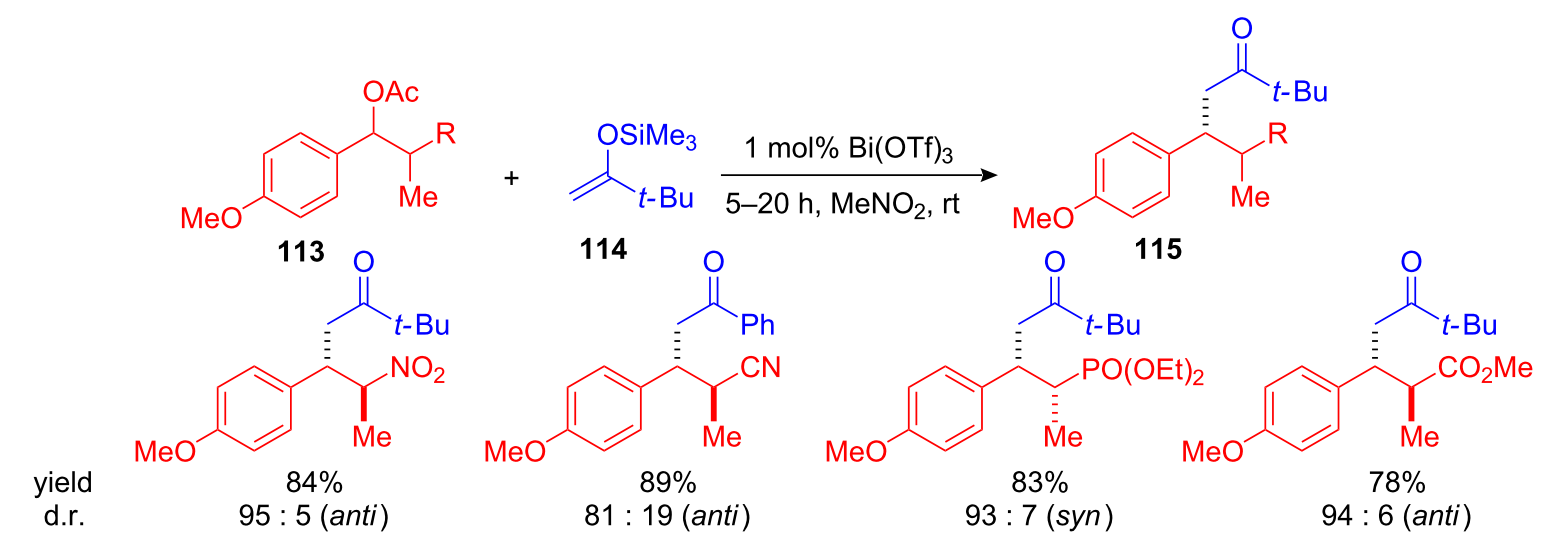

Scheme 42: $\mathrm{Bi}(\mathrm{OTf})_{3}$-catalyzed alkylation of $\alpha$-chiral benzyl acetates with silyl enol ethers.

Similar methods using silyl enol ethers were subsequently developed involving $\mathrm{Bi}(\mathrm{OTf})_{3}$ as Lewis acid catalyst [117,118] While bismuth-catalyzed arylation of benzyl alcohols proceeded only at temperatures between 55 and $100{ }^{\circ} \mathrm{C}$, the reaction of $p$-methoxybenzyl acetates $\mathbf{1 1 3}$ with silyl enol ethers $\mathbf{1 1 4}$ took place even at ambient temperatures to give the desired products 115 (Scheme 42) [118]. Again different chiral benzyl acetates were efficiently substituted employing low amounts of catalyst (1-5 mol\%). While nitro-, cyano- and methyl ester derivatives gave remarkable anti-selectivity, the corresponding $\alpha$-phosphonate showed high syn-selectivity. In general, the diastereoselectivity can be explained by comparing the A-values (an estimation of the steric demand) of the $\alpha$-functional groups. If the A-value of the functional group is higher than the A-value of the methyl group, Re-attack is favoured giving the corresponding anti products and vice versa [119].
In addition to benzyl alcohols and propargyl alcohols, acetates can also be used in diastereoselective FC alkylations. Again $\mathrm{Bi}(\mathrm{OTf})_{3}$ was the Lewis acid of choice. With $10 \mathrm{~mol} \%$ of catalyst the $\alpha$-tert-butyl-substituted propargyl acetates $\mathbf{1 1 6}$ could be substituted with silyl enol ethers, allylsilane and various arenes and heteroarenes to give the desired alkylated alkynes $\mathbf{1 1 7}$ in high yields and excellent anti diastereoselectivities of up to 99 : 1 d.r. (Scheme 43) [117].

Treatment of chiral $\beta$-hydroxy esters with aromatic and aliphatic nitriles in the presence of catalytic amounts of $\mathrm{TfOH}$ and subsequent hydrolysis in a Ritter-type reaction led to the desired anti $\alpha$-amino esters with high diastereoselectivities [120].

Next to the described developments, Cozzi et al. reported that enantioenriched ferrocenyl alcohols 118 can be efficiently

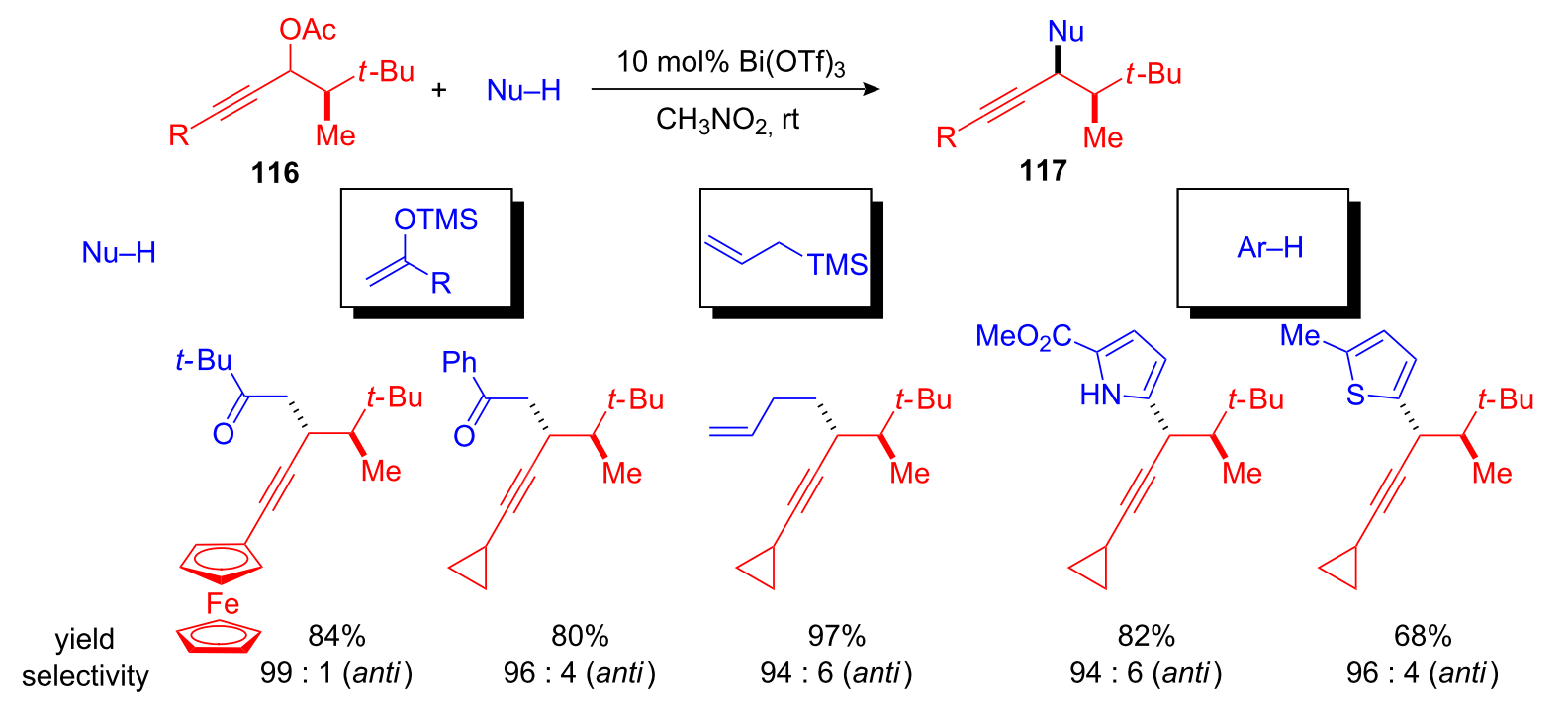

Scheme 43: $\mathrm{Bi}(\mathrm{OTf})_{3}$-catalyzed diastereoselective substitution of propargyl acetates. 


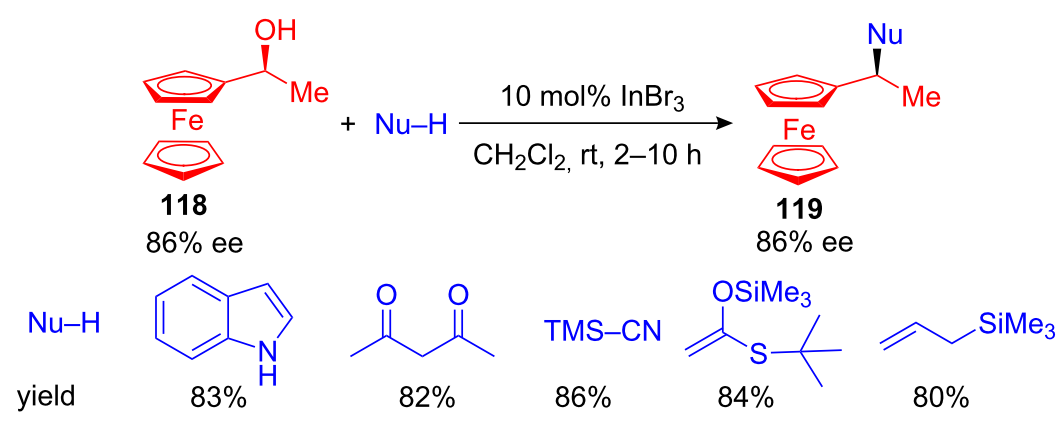

Scheme 44: Nucelophilic substitution of enantioenriched ferrocenyl alcohols.

substituted with various C-nucleophiles. Applying $10 \mathrm{~mol} \%$ of $\mathrm{InBr}_{3}$ the desired substituted ferrocenyl derivatives 119 were isolated in high yields under ambient conditions (Scheme 44). The configuration was retained during the nucleophilic substitution. The optically active ferrocenyl alcohols can be easily synthesised from the corresponding ferrocenyl ketone precursor via an enantioselective aminoindanol/ $\mathrm{BH}_{3}$ reduction [121]. The same authors reported shortly after their initial finding a highly efficient substitution of ferrocenyl alcohols in water, without the need of any Lewis-acid catalyst [50]. A comparable, nonchiral version of this $\mathrm{C}-\mathrm{C}$ bond forming reaction using ceric ammonium nitrate has recently been developed [122].
A first catalytic enantioselective Friedel-Crafts alkylation with propargyl alcohols as electrophile has been developed by Nishibayashi and co-workers. Chirality was introduced by a thiolate-bridged diruthenium complex which is based on optically active disulfide ligand 120. 2-Alkylfurans as well as $N, N$ dimethylaniline were efficiently utilized as nucleophiles and the corresponding highly valuable optically active propargylated aromatic compounds $\mathbf{1 2 2}$ were isolated in moderate yield but with excellent enantioselectivities of up to $94 \%$ ee (Scheme 45) [97].

This milestone in the catalysis of the Friedel-Crafts alkylation should be considered a good starting point for the development

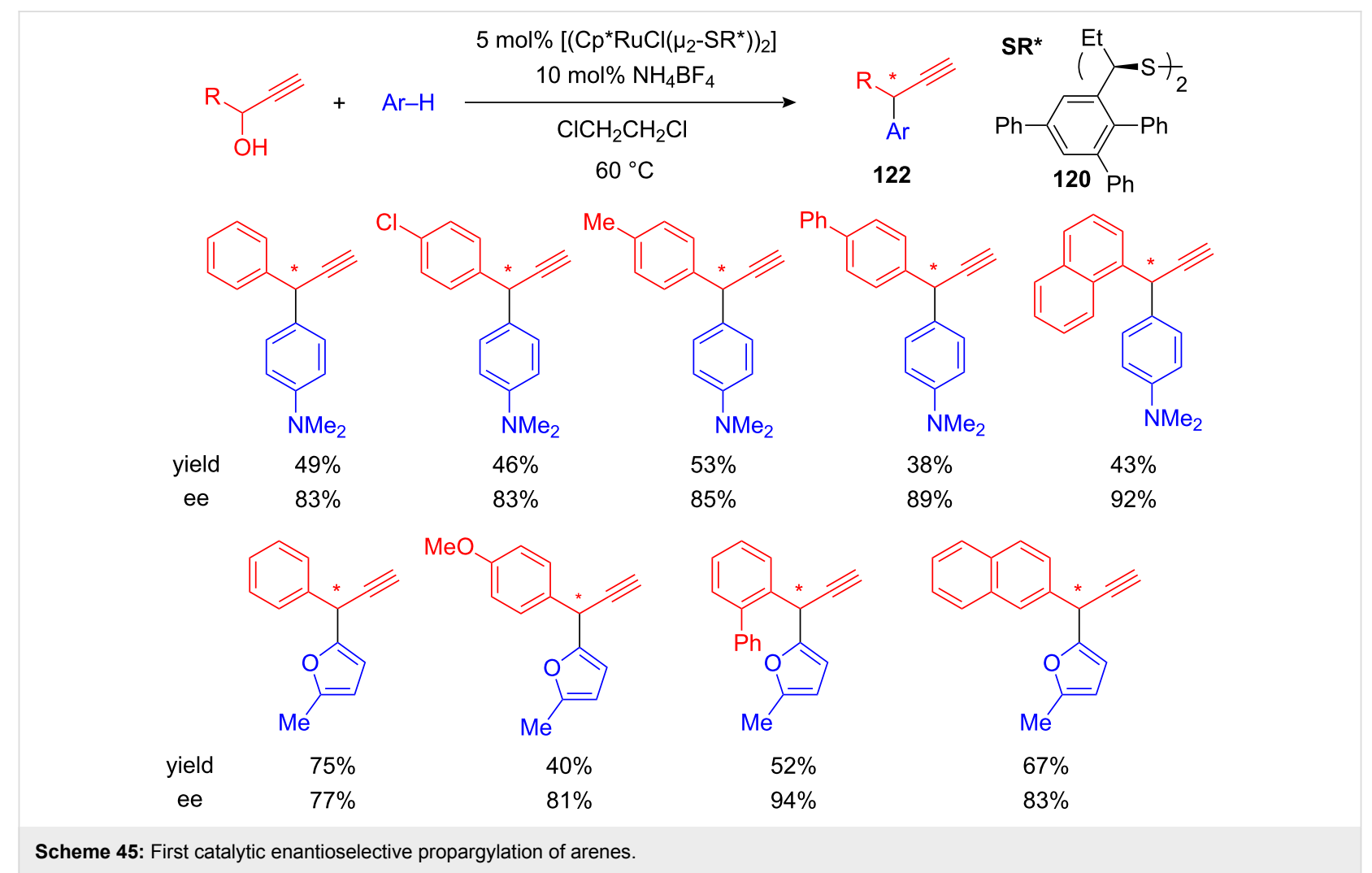

Scheme 45: First catalytic enantioselective propargylation of arenes 
of other catalytic enantioselective FC alkylations, using not only propargyl- but also allyl- or benzyl alcohols as electrophilic components.

\section{Future Perspectives}

Despite the great efforts that have been undertaken in the last decade with catalytic FC alkylations, there are still major challenges that need addressing. To the best of our knowledge no catalytic enantioselective Friedel-Crafts reactions leading to enantioenriched 1,1-diarylalkanes are known. Chiral, bifunctional Lewis- or Brønsted acid catalysts are required that stabilize the transient carbocations and are able to mediate enantioselective $\mathrm{S}_{\mathrm{N}} 1$ reactions.

Moreover, Friedel-Crafts alkylations of arenes bearing free amines or nitrogen-containing heterocycles will be a great advance in this area. This increase in functional group tolerance would allow the use of the Friedel-Crafts reactions in the late stages of complex natural product synthesis or in the preparation of biological relevant molecules, including pharmaceuticals and agrochemicals. Furthermore, the extension of substrate scope away from $\pi$-activated alcohols and double bonds to less reactive alkyl alcohols is a major goal, and will finally eliminate the need for haloalkanes in FC alkylations.

\section{Acknowledgements}

The authors acknowledge Evonik Degussa for the financial support and the Fonds der Chemischen Industrie for a stipend to B. J. N.

\section{References}

1. Friedel, C.; Crafts, J. M. J. Chem. Soc. 1877, 32, 725-791. doi:10.1039/JS8773200725

2. Yamauchi, T.; Hattori, K.; Mizutaki, S.; Tamaki, K.; Uemura, S. Bull. Chem. Soc. Jpn. 1986, 59, 3617-3620. doi:10.1246/bcsj.59.3617

3. Tsuchimoto, T.; Tobita, K.; Hiyama, T.; Fukuzawa, S.-i. Synlett 1996, 557-559. doi:10.1055/s-1996-5498

4. Tsuchimoto, T.; Tobita, K.; Hiyama, T.; Fukuzawa, S.-i. J. Org. Chem. 1997, 62, 6997-7005. doi:10.1021/j0970599u

5. Shimizu, I.; Khien, K. M.; Nagatomo, M.; Nakajima, T.; Yamamoto, A. Chem. Lett. 1997, 851-852. doi:10.1246/cl.1997.851

6. Sarca, V. D.; Laali, K. K. Green Chem. 2006, 8, 615-620. doi:10.1039/b603176e

7. Tsuchimoto, T.; Hiyama, T.; Fukuzawa, S.-i. Chem. Commun. 1996, 2345-2346. doi:10.1039/CC9960002345

8. Shiina, I.; Suzuki, M. Tetrahedron Lett. 2002, 43, 6391-6394. doi:10.1016/S0040-4039(02)01376-X

9. Noji, M.; Ohno, T.; Fuji, K.; Futaba, N.; Tajima, H.; Ishii, K. J. Org. Chem. 2003, 68, 9340-9347. doi:10.1021/jo034255h

10. Sun, H.-B.; Li, B.; Chen, S.; Li, J.; Hua, R. Tetrahedron 2007, 63, 10185-10188. doi:10.1016/j.tet.2007.07.093

11. Sun, G.; Sun, H.; Wang, Z.; Zhou, M.-M. Synlett 2008, 1096-1100. doi:10.1055/s-2008-1042917
12. Yadav, J. S.; Bhunia, D. C.; Krishna, K. V.; Srihari, P. Tetrahedron Lett. 2007, 48, 8306-8310. doi:10.1016/j.tetlet.2007.09.140

13. Choudhury, J.; Podder, S.; Roy, S. J. Am. Chem. Soc. 2005, 127, 6162-6163. doi:10.1021/ja0506004

14. Podder, S.; Choudhury, J.; Roy, S. J. Org. Chem. 2007, 72, 3129-3132. doi:10.1021/jo0625094

15. Motokura, K.; Nakagiri, N.; Mizugaki, T.; Ebitani, K.; Kaneda, K. J. Org. Chem. 2007, 72, 6006-6015. doi:10.1021/jo070416w

16. Yamamoto, Y.; Itonaga, K. Chem.-Eur. J. 2008, 14, 10705-10715. doi:10.1002/chem.200801105

17. Le Bras, J.; Muzart, J. Tetrahedron 2007, 63, 7942-7948. doi:10.1016/j.tet.2007.05.070

18. Sanz, R.; Martínez, A.; Miguel, D.; Álvarez-Gutiérrez, J. M.; Rodríguez, F. Adv. Synth. Catal. 2006, 348, 1841-1845. doi:10.1002/adsc.200606183

19. Sanz, R.; Miguel, D.; Álvarez-Gutiérrez, J. M.; Rodríguez, F. Synlett 2008, 975-978. doi:10.1055/s-2008-1072584

20. Liu, Y.-L.; Liu, L.; Wang, Y.-L.; Han, Y.-C.; Wang, D.; Chen, Y.-J. Green Chem. 2008, 10, 635-640. doi:10.1039/b719278a

21. Srihari, P.; Bhunia, D. C.; Sreedhar, P.; Yadav, J. S. Synlett 2008, 1045-1049. doi:10.1055/s-2008-1072652

22. Sun, G.; Wang, Z. Tetrahedron Lett. 2008, 49, 4929-4932. doi:10.1016/j.tetlet.2008.05.146

23. Mertins, K.; lovel, I.; Kischel, J.; Zapf, A.; Beller, M. Adv. Synth. Catal. 2006, 348, 691-695. doi:10.1002/adsc.200505433

24. Mertins, K.; lovel, I.; Kischel, J.; Zapf, A.; Beller, M. Angew. Chem. 2005, 117, 242-246. doi:10.1002/ange.200460666 Angew. Chem., Int. Ed. 2005, 44, 238-242. doi:10.1002/anie.200460666

25. Iovel, I.; Mertins, K.; Kischel, J.; Zapf, A.; Beller, M. Angew. Chem. 2005, 117, 3981-3985. doi:10.1002/ange.200462522 Angew. Chem., Int. Ed. 2005, 44, 3913-3917. doi:10.1002/anie.200462522

26. Wang, B.-Q.; Xiang, S.-K.; Sun, Z.-P.; Guan, B.-T.; Hu, P.; Zhao, K.-Q.; Shi, Z.-J. Tetrahedron Lett. 2008, 49, 4310-4312. doi:10.1016/j.tetlet.2008.04.117

27. Kischel, J.; Mertins, K.; Michalik, D.; Zapf, A.; Beller, M. Adv. Synth. Catal. 2007, 349, 865-870. doi:10.1002/adsc.200600497

28. Rueping, M.; Nachtsheim, B. J.; Kuenkel, A. Org. Lett. 2007, 9 , 825-828. doi:10.1021/ol063048b

29. Yasuda, M.; Somyo, T.; Baba, A. Angew. Chem. 2006, 118, 807-810. doi:10.1002/ange.200503263 Angew. Chem., Int. Ed. 2006, 45, 793-796. doi:10.1002/anie.200503263

30. Yadav, J. S.; Reddy, B. V. S.; Rao, K. V. R.; Narender, R. Tetrahedron Lett. 2009, 50, 3963-3965. doi:10.1016/j.tetlet.2009.04.088

31. Ahmad, R.; Riahi, A.; Langer, P. Tetrahedron Lett. 2009, 50, 1490-1492. doi:10.1016/j.tetlet.2009.01.079

32. Kothandaraman, P.; Rao, W.; Zhang, X.; Chan, P. W. H. Tetrahedron 2009, 65, 1833-1838. doi:10.1016/j.tet.2008.11.102

33. Yang, H.; Fang, L.; Zhang, M.; Zhu, C. Eur. J. Org. Chem. 2009, 666-672. doi:10.1002/ejoc.200800976

34. Fan, J.; Wang, Z. Chem. Commun. 2008, 5381-5383. doi:10.1039/b812046c

35. Li, Z.; Duan, Z.; Wang, H.; Tian, R.; Zhu, Q.; Wu, Y. Synlett 2008, 2535-2539. doi:10.1055/s-2008-1078216

36. Wang, G.-W.; Shen, Y.-B.; Wu, X.-L. Eur. J. Org. Chem. 2008, 4999-5004. doi:10.1002/ejoc.200800624 
37. Yadav, J. S.; Reddy, B. V. S.; Pandurangam, T.; Rao, K. V. R.; Praneeth, K.; Kumar, G. G. K. S. N.; Madavi, C.; Kunwar, A. C. Tetrahedron Lett. 2008, 49, 4296-4301. doi:10.1016/j.tetlet.2008.04.126

38. Feng, X.; Tan, Z.; Chen, D.; Shen, Y.; Guo, C.-C.; Xiang, J.; Zhu, C. Tetrahedron Lett. 2008, 49, 4110-4112. doi:10.1016/j.tetlet.2008.04.142

39. Huang, W.; Wang, J.; Shen, Q.; Zhou, X. Tetrahedron 2007, 63, 11636-11643. doi:10.1016/j.tet.2007.08.114

40. Liu, P. N.; Zhou, Z. Y.; Lau, C. P. Chem.-Eur. J. 2007, 13, 8610-8619. doi:10.1002/chem.200700705

41. Noji, M.; Konno, Y.; Ishii, K. J. Org. Chem. 2007, 72, 5161-5167. doi:10.1021/jo0705216

42. Huang, W.; Wang, J.; Shen, Q.; Zhou, X. Tetrahedron Lett. 2007, 48, 3969-3973. doi:10.1016/j.tetlet.2007.04.047

43. Sanz, R.; Miguel, D.; Martínez, A.; Álvarez-Gutiérrez, J. M.; Rodríguez, F. Org. Lett. 2007, 9, 2027-2030. doi:10.1021/ol070624a

44. Jana, U.; Biswas, S.; Maiti, S. Tetrahedron Lett. 2007, 48, 4065-4069. doi:10.1016/j.tetlet.2007.04.017

45. Sanz, R.; Miguel, D.; Martínez, A.; Álvarez-Gutiérrez, J. M.; Rodríguez, F. Org. Lett. 2007, 9, 727-730. doi:10.1021/ol0631298

46. Rueping, M.; Nachtsheim, B. J.; leawsuwan, W. Adv. Synth. Catal. 2006, 348, 1033-1037. doi:10.1002/adsc.200606068

47. Wang, F.; Ueda, W. Chem. Commun. 2008, 3196-3198. doi:10.1039/b803205j

48. Wang, F.; Ueda, W. Chem.-Eur. J. 2009, 15, 742-753. doi:10.1002/chem.200801153

49. Shirakawa, S.; Kobayashi, S. Org. Lett. 2007, 9, 311-314. doi:10.1021/ol062813j

50. Cozzi, P. G.; Zoli, L. Angew. Chem. 2008, 120, 4230-4234. doi:10.1002/ange.200800622

Angew. Chem., Int. Ed. 2008, 47, 4162-4166. doi:10.1002/anie.200800622

51. Prades, A.; Corberán, R.; Poyatos, M.; Peris, E. Chem.-Eur. J. 2009, 15, 4610-4613. doi:10.1002/chem.200802740

52. Poulsen, T. B.; Jørgensen, K. A. Chem. Rev. 2008, 108, 2903-2915. doi:10.1021/cr078372e

53. Bandini, M.; Melloni, A.; Umani-Ronchi, A. Angew. Chem. 2004, 116, 560-566. doi:10.1002/ange.200301679

Angew. Chem., Int. Ed. 2004, 43, 550-556. doi:10.1002/anie.200301679

54. Tsogoeva, S. B. Eur. J. Org. Chem. 2007, 1701-1716. doi:10.1002/ejoc.200600653

55. Bandini, M.; Eichholzer, A.; Umani-Ronchi, A. Mini-Rev. Org. Chem. 2007, 4, 115-124. doi:10.2174/157019307780599270

56. Murai, S.; Kakiuchi, F.; Sekine, S.; Tanaka, Y.; Kamatani, A.; Sonoda, M.; Chatani, N. Nature 1993, 366, 529-531. doi:10.1038/366529a0

57. Kakiuchi, F.; Murai, S. Acc. Chem. Res. 2002, 35, 826-834. doi:10.1021/ar960318p

58. Kischel, J.; Jovel, I.; Mertins, K.; Zapf, A.; Beller, M. Org. Lett. 2006, 8, 19-22. doi:10.1021/ol0523143

59. Rueping, M.; Nachtsheim, B. J.; Scheidt, T. Org. Lett. 2006, 8, 3717-3719. doi:10.1021/ol0612962

60. Rueping, M.; Nachtsheim, B. J.; Kuenkel, A. Synlett 2007, 1391-1394. doi:10.1055/s-2007-980363

61. Sun, H.-B.; Li, B.; Hua, R.; Yin, Y. Eur. J. Org. Chem. 2006, 4231-4236. doi:10.1002/ejoc.200600390

62. Chu, C.-M.; Huang, W.-J.; Liu, J.-T.; Yao, C.-F. Tetrahedron Lett. 2007, 48, 6881-6885. doi:10.1016/j.tetlet.2007.07.178
63. Xiao, Y.-P.; Liu, X.-Y.; Che, C.-M. J. Organomet. Chem. 2009, 694, 494-501. doi:10.1016/j.jorganchem.2008.07.035

64. Wang, M.-Z.; Wong, M.-K.; Che, C.-M. Chem.-Eur. J. 2008, 14, 8353-8364. doi:10.1002/chem.200800040

65. Liu, C.; Bender, C. F.; Han, X.; Widenhoefer, R. A. Chem. Commun. 2007, 3607-3618. doi:10.1039/b615698c

66. Müller, T. E.; Hultzsch, K. C.; Yus, M.; Foubelo, F.; Tada, M. Chem. Rev. 2008, 108, 3795-3892. doi:10.1021/cr0306788

67. Beller, M.; Thiel, O. R.; Trauthwein, H. Synlett 1999, 243-245. doi:10.1055/s-1999-2579

68. Uchimaru, Y. Chem. Commun. 1999, 1133-1134. doi:10.1039/a902240f

69. Kaspar, L. T.; Fingerhut, B.; Ackermann, L. Angew. Chem. 2005, 117, 6126-6128. doi:10.1002/ange.200501423 Angew. Chem., Int. Ed. 2005, 44, 5972-5974. doi:10.1002/anie.200501423

70. Anderson, L. L.; Arnold, J.; Bergman, R. G. J. Am. Chem. Soc. 2005, 127, 14542-14543. doi:10.1021/ja053700i

71. Cherian, A. E.; Domski, G. J.; Rose, J. M.; Lobkovsky, E. B.; Coates, G. W. Org. Lett. 2005, 7, 5135-5137. doi:10.1021/ol051916j

72. Shimizu, I.; Sakamoto, T.; Kawaragi, S.; Maruyama, Y.; Yamamoto, A. Chem. Lett. 1997, 137-138. doi:10.1246/cl.1997.137

73. Nishibayashi, Y.; Yamanashi, M.; Takagi, Y.; Hidai, M. Chem. Commun. 1997, 859-860. doi:10.1039/a701115f

74. Malkov, A. V.; Davis, S. L.; Baxendale, I. R.; Mitchell, W. L.; Kočovský, P. J. Org. Chem. 1999, 64, 2751-2764. doi:10.1021/jo982178y

75. Malkov, A. V.; Spoor, P.; Vinader, V.; Kočovský, P. J. Org. Chem. 1999, 64, 5308-5311. doi:10.1021/jo990372u

76. Yamamoto, Y.; Itonaga, K. Org. Lett. 2009, 11, 717-720. doi:10.1021/ol802800s

77. Bonrath, W.; Dittel, C.; Giraudi, L.; Netscher, T.; Pabst, T. Catal. Today 2007, 121, 65-70. doi:10.1016/j.cattod.2006.11.022

78. Bonrath, W.; Haas, A.; Hoppmann, E.; Netscher, T.; Pauling, H.; Schager, F.; Wildermann, A. Adv. Synth. Catal. 2002, 344, 37-39. doi:10.1002/1615-4169(200201)344:1<37::AID-ADSC37>3.0.CO;2-4

79. Hasegawa, A.; Ishihara, K.; Yamamoto, H. Angew. Chem. 2003, 115, 5909-5911. doi:10.1002/ange.200352382 Angew. Chem., Int. Ed. 2003, 42, 5731-5733. doi:10.1002/anie.200352382

80. Rao, W.; Chan, P. W. H. Org. Biomol. Chem. 2008, 6, 2426-2433. doi:10.1039/b805067h

81. Kimura, M.; Fukasaka, M.; Tamaru, Y. Synthesis 2006, 3611-3616. doi:10.1055/s-2006-950220

82. Kimura, M.; Futamata, M.; Mukai, R.; Tamaru, Y. J. Am. Chem. Soc. 2005, 127, 4592-4593. doi:10.1021/ja0501161

83. Usui, I.; Schmidt, S.; Keller, M.; Breit, B. Org. Lett. 2008, 10, 1207-1210. doi:10.1021/ol800073v

84. Yadav, J. S.; Reddy, B. V. S.; Aravind, S.; Kumar, G. G. K. S. N.; Reddy, A. S. Tetrahedron Lett. 2007, 48, 6117-6120. doi:10.1016/j.tetlet.2007.06.144

85. Jana, U.; Maiti, S.; Biswas, S. Tetrahedron Lett. 2007, 48, 7160-7163. doi:10.1016/j.tetlet.2007.07.208

86. Zaitsev, A. B.; Gruber, S.; Plüss, P. A.; Pregosin, P. S.; Veiros, L. F.; Wörle, M. J. Am. Chem. Soc. 2008, 130, 11604-11605. doi:10.1021/ja804379k

87. Zaitsev, A. B.; Gruber, S.; Pregosin, P. S. Chem. Commun. 2007, 4692-4693. doi:10.1039/b710763c

88. Nieves, I. F.; Schott, D.; Gruber, S.; Pregosin, P. S. Helv. Chim. Acta 2007, 90, 271-276. doi:10.1002/hlca.200790030 
89. Namba, K.; Yamamoto, H.; Sasaki, I.; Mori, K.; Imagawa, H.; Nishizawa, M. Org. Lett. 2008, 10, 1767-1770. doi:10.1021/ol800450x

90. Bandini, M.; Eichholzer, A.; Kotrusz, P.; Umani-Ronchi, A. Adv. Synth. Catal. 2008, 350, 531-536. doi:10.1002/adsc.200700607

91. Bandini, M.; Eichholzer, A.; Kotrusz, P.; Tragni, M.; Troisi, S.; Umani-Ronchi, A. Adv. Synth. Catal. 2009, 351, 319-324. doi:10.1002/adsc.200800628

92. Huang, W.; Hong, L.; Zheng, P.; Liu, R.; Zhou, X. Tetrahedron 2009, 65, 3603-3610. doi:10.1016/j.tet.2009.03.007

93. Nicholas, K. M. Acc. Chem. Res. 1987, 20, 207-214. doi:10.1021/ar00138a001

94. Nishibayashi, Y.; Yoshikawa, M.; Inada, Y.; Hidai, M.; Uemura, S. J. Am. Chem. Soc. 2002, 124, 11846-11847. doi:10.1021/ja027023t

95. Nishibayashi, Y.; Inada, Y.; Yoshikawa, M.; Hidai, M.; Uemura, S. Angew. Chem. 2003, 115, 1533-1536. doi:10.1002/ange.200250532 Angew. Chem., Int. Ed. 2003, 42, 1495-1498. doi:10.1002/anie.200250532

96. Nishibayashi, Y.; Inada, Y.; Hidai, M.; Uemura, S. J. Am. Chem. Soc. 2002, 124, 7900-7901. doi:10.1021/ja026168x

97. Matsuzawa, H.; Miyake, Y.; Nishibayashi, Y. Angew. Chem. 2007, 119, 6608-6611. doi:10.1002/ange.200701261 Angew. Chem., Int. Ed. 2007, 46, 6488-6491. doi:10.1002/anie.200701261

98. Murakami, M.; Hori, S. J. Am. Chem. Soc. 2003, 125, 4720-4721. doi:10.1021/ja029829z

99. Srihari, P.; Reddy, J. S. S.; Mandal, S. S.; Satyanarayana, K.; Yadav, J. S. Synthesis 2008, 1853-1860. doi:10.1055/s-2008-1067083

100.Sanz, R.; Martínez, A.; Álvarez-Gutiérrez, J. M.; Rodríguez, F. Eur. J. Org. Chem. 2006, 1383-1386. doi:10.1002/ejoc.200500960

101.Zhan, Z.-p.; Yu, J.-I.; Liu, H.-j.; Cui, Y.-y.; Yang, R.-f.; Yang, W.-z.; Li, J.-p. J. Org. Chem. 2006, 71, 8298-8301. doi:10.1021/jo061234p

102.Zhan, Z.-P.; Cui, Y.-Y.; Liu, H.-J. Tetrahedron Lett. 2006, 47, 9143-9146. doi:10.1016/j.tetlet.2006.10.038

103.Zhan, Z.-p.; Yang, W.-Z.; Yang, R.-f.; Yu, J.-I.; Li, J.-p.; Liu, H.-j. Chem. Commun. 2006, 3352-3354. doi:10.1039/b606470a

104. Yadav, J. S.; Reddy, B. V. S.; Rao, K. V. R.; Kumar, G. G. K. S. N. Tetrahedron Lett. 2007, 48, 5573-5576. doi:10.1016/j.tetlet.2007.04.056

105. Bustelo, E.; Dixneuf, P. H. Adv. Synth. Catal. 2005, 347, 393-397. doi:10.1002/adsc. 200404219

106. Fischmeister, C.; Toupet, L.; Dixneuf, P. H. New J. Chem. 2005, 29, 765-768. doi:10.1039/b501305d

107.Bustelo, E.; Dixneuf, P. H. Adv. Synth. Catal. 2007, 349, 933-942. doi:10.1002/adsc.200600512

108. Kennedy-Smith, J. J.; Young, L. A.; Toste, F. D. Org. Lett. 2004, 6, 1325-1327. doi:10.1021/ol049649p

109.Srihari, P.; Bhunia, D. C.; Sreedhar, P.; Mandal, S. S.; Reddy, J. S. S.; Yadav, J. S. Tetrahedron Lett. 2007, 48, 8120-8124. doi:10.1016/j.tetlet.2007.09.123

110. Yoshimatsu, M.; Otani, T.; Matsuda, S.; Yamamoto, T.; Sawa, A. Org. Lett. 2008, 10, 4251-4254. doi:10.1021/ol801533p

111.Li, C.; Wang, J. J. Org. Chem. 2007, 72, 7431-7434. doi:10.1021/jo0709192

112. Mühlthau, F.; Schuster, O.; Bach, T. J. Am. Chem. Soc. 2005, 127, 9348-9349. doi:10.1021/ja050626v

113.Mühlthau, F.; Stadler, D.; Goeppert, A.; Olah, G. A.; Prakash, G. K. S.; Bach, T. J. Am. Chem. Soc. 2006, 128, 9668-9675.

doi:10.1021/ja062102g
114.Stadler, D.; Mühlthau, F.; Rubenbauer, P.; Herdtweck, E.; Bach, T. Synlett 2006, 2573-2576. doi:10.1055/s-2006-951471

115. Chung, J. Y. L.; Mancheno, D.; Dormer, P. G.; Variankaval, N.; Ball, R. G.; Tsou, N. N. Org. Lett. 2008, 10, 3037-3040. doi:10.1021/ol800858c

116. Rubenbauer, P.; Bach, T. Adv. Synth. Catal. 2008, 350, 1125-1130. doi:10.1002/adsc. 200700600

117.Rubenbauer, P.; Herdtweck, E.; Strassner, T.; Bach, T. Angew. Chem. 2008, 120, 10260-10263.

doi:10.1002/ange.200804025

Angew. Chem., Int. Ed. 2008, 47, 10106-10109. doi:10.1002/anie.200804025

118. Rubenbauer, P.; Bach, T. Tetrahedron Lett. 2008, 49, 1305-1309. doi:10.1016/j.tetlet.2007.12.092

119. Stadler, D.; Bach, T. Chem.-Asian J. 2008, 3, 272-284. doi:10.1002/asia.200700241

120. Rubenbauer, P.; Bach, T. Chem. Commun. 2009, 2130-2132. doi:10.1039/b901937e

121. Vicennati, P.; Cozzi, P. G. Eur. J. Org. Chem. 2007, 2248-2253. doi:10.1002/ejoc.200700146

122.Xu, X.; Jiang, R.; Zhou, X.; Liu, Y.; Ji, S.; Zhang, Y. Tetrahedron 2009, 65, 877-882. doi:10.1016/j.tet.2008.11.048

\section{License and Terms}

This is an Open Access article under the terms of the Creative Commons Attribution License (http://creativecommons.org/licenses/by/2.0), which permits unrestricted use, distribution, and reproduction in any medium, provided the original work is properly cited.

The license is subject to the Beilstein Journal of Organic Chemistry terms and conditions:

(http://www.beilstein-journals.org/bjoc)

The definitive version of this article is the electronic one which can be found at: doi:10.3762/bjoc. 6.6 